\title{
Identification of a Signaling Pathway Activated Specifically in the Somatodendritic Compartment by a Heparan Sulfate That Regulates Dendrite Growth
}

\author{
Sophie Calvet, ${ }^{1}$ Patrick Doherty, ${ }^{2}$ and Alain Prochiantz ${ }^{1}$ \\ ${ }^{1}$ Centre National de la Recherche Scientifique, Unité de Recherche Associée 1414, Ecole Normale Supérieure, 75230 \\ Paris Cedex 05, France, and 2Department of Experimental Pathology, United Medical and Dental Schools, Guy's Hospital, \\ London SE1 9RT, United Kingdom
}

In two earlier reports we demonstrated that natural heparan sulfate, but not dermatan or chondroitin sulfate glycosaminoglycans, stimulate axonal elongation and inhibit dendrite growth in vitro (Lafont et al., 1992). The latter specific effect on dendrite elongation was reproduced by chemically synthesized heparan sulfates and by SR 80037A, a purified sulfated and hexanoylated heparin fragment (Lafont et al., 1994). Adding radioactive SR $80037 \mathrm{~A}$ to purified neurons demonstrated the existence, at the neuronal surface, of heparan sulfate-specific and saturable binding sites, suggesting that SR $80037 \mathrm{~A}$ activates specific signal transduction pathways. In the present study, using rat or mouse neurons from the embryonic cortex, we show that SR 80037A signaling involves one or several G-coupled receptor or receptors, small GTPases $\rho \mathrm{A}$ and/or $\rho \mathrm{C}$, and one or several PKCs. We also demonstrate that the rapid soma rounding elicited by SR $80037 \mathrm{~A}$ does not require protein synthesis but that the long-term effect on dendrite initiation requires protein synthesis in a short period after the addition of the heparan sulfate. Finally, by preparing membranes from the somatodendritic or axonal compartments we demonstrate that the identified signaling pathway is activated by SR $80037 \mathrm{~A}$ primarily in the somatodendritic compartment and is not sensitive to the addition of a dermatan sulfate glycosaminoglycan that does not induce the axonal phenotype by impairing dendrite initiation and elongation.

Key words: neurons in culture; neuronal polarity; glycosaminoglycans; signal transduction; dendrite growth inhibition; cell rounding; cell permeable peptides
Neurons are highly polarized cells with characteristic axons and dendrites. This polarity is established during development through interactions of the neurons with cellular partners, in particular astrocytes (Prochiantz, 1995) or Schwann cells (Lein et al., 1995), and molecular signals (Higgins et al., 1997). Among the latter are growth factors, such as neurotrophins (McAllister et al., 1997) or bone morphogenetic proteins (Lein et al., 1995) and matrix molecules (Chamak and Prochiantz, 1989; Lafont et al., 1992; Prochiantz, 1995).

An important aspect of neuronal polarity is the regional specificity of the interactions taking place between neurons and their environment. Indeed, by coculturing astrocytes and neurons from different regions, it was observed that neurons will develop, or not, their dendritic arbor, depending on the anatomical origin of the astrocytes (Denis-Donini et al., 1984; Chamak et al., 1987; Rousselet et al., 1988, 1990; Qian et al., 1992; Le Roux and Reh, 1994). Recently, using slice cultures, it was further demonstrated that neuronal polarity is regulated by different neurotrophins in layers 4 and 6 of the developing cortex (McAllister et al., 1997).

The influence of the anatomical origin of astrocytes on neuronal polarity led us to investigate the activity of molecules present in astrocyte-conditioned medium and to observe that glycosami-

\footnotetext{
Received June 25, 1998; revised Sept. 10, 1998; accepted Sept. 22, 1998.

This work was supported by Centre National de la Recherche Scientifique, Ecole Normale Supérieure, Sanofi-Recherche, and EC Program BIOMED 950524. We thank Dr. M. Petitou (Sanofi-Recherche) for his participation in several practical and theoretical aspects of this work.

Correspondence should be addressed to A. Prochiantz, Centre National de la Recherche Scientifique, Unité de Recherche Associée 1414, Ecole Normale Supérieure, 46 rue d’Ulm, 75230 Paris Cedex 05, France.

Copyright (C) 1998 Society for Neuroscience $\quad 0270-6474 / 98 / 189751-15 \$ 05.00 / 0$
}

noglycans (GAGs) regulate neuronal polarity (Lafont et al., 1992). Interestingly, heparan sulfates (HSs) induced an axonal phenotype (long axons and no or short dendrites), whereas dermatan and chondroitin sulfates had a general trophic effect on all neurites or favored dendrite elongation. Because GAGs are composed of a combination of heparan, chondroitin, and dermatan motifs, it appeared that elementary carbohydrate units might participate in the specificity of neuroastroglial interactions revealed by polarity studies.

We, therefore, screened a GAG bank composed of synthetic disaccharides to hexasaccharides for their effects on neuronal polarity (Lafont et al., 1994). We found that, when active, sugars from the HS series, as well as SR 80037A (a purified heparinderived heparan sulfate) decrease neuron-substratum adhesion, inhibit dendrite outgrowth, and either stimulate or do not affect axonal elongation, whereas synthetic dermatan sulfates (DSs) have the opposite influence on neuronal differentiation. These effects were observed on all embryonic rat or mouse neurons tested, and the sugars were only active in solution. Substratumbound GAGs lost their ability to regulate polarity. We also observed that neurons express $3-5 \times 10^{5}$ HS-binding sites $\left(K_{\mathrm{D}}, 1\right.$ $\mu \mathrm{M})$ with a clear structural specificity, because only SR $80037 \mathrm{~A}$ or active HS-like GAGs competed with labeled SR 80037A for binding to neurons, and the DS-derived GAGs were inactive, even at high concentrations.

These results suggested that HS, natural or synthetic, bind specific receptors and activate pathways related to dendrite growth. We now demonstrate that SR 80037A signaling involves G-coupled receptor(s), small $\rho$ GTPases, and one or several $\mathrm{PKC}$ and that the HS signaling pathway, which is only activated 
A
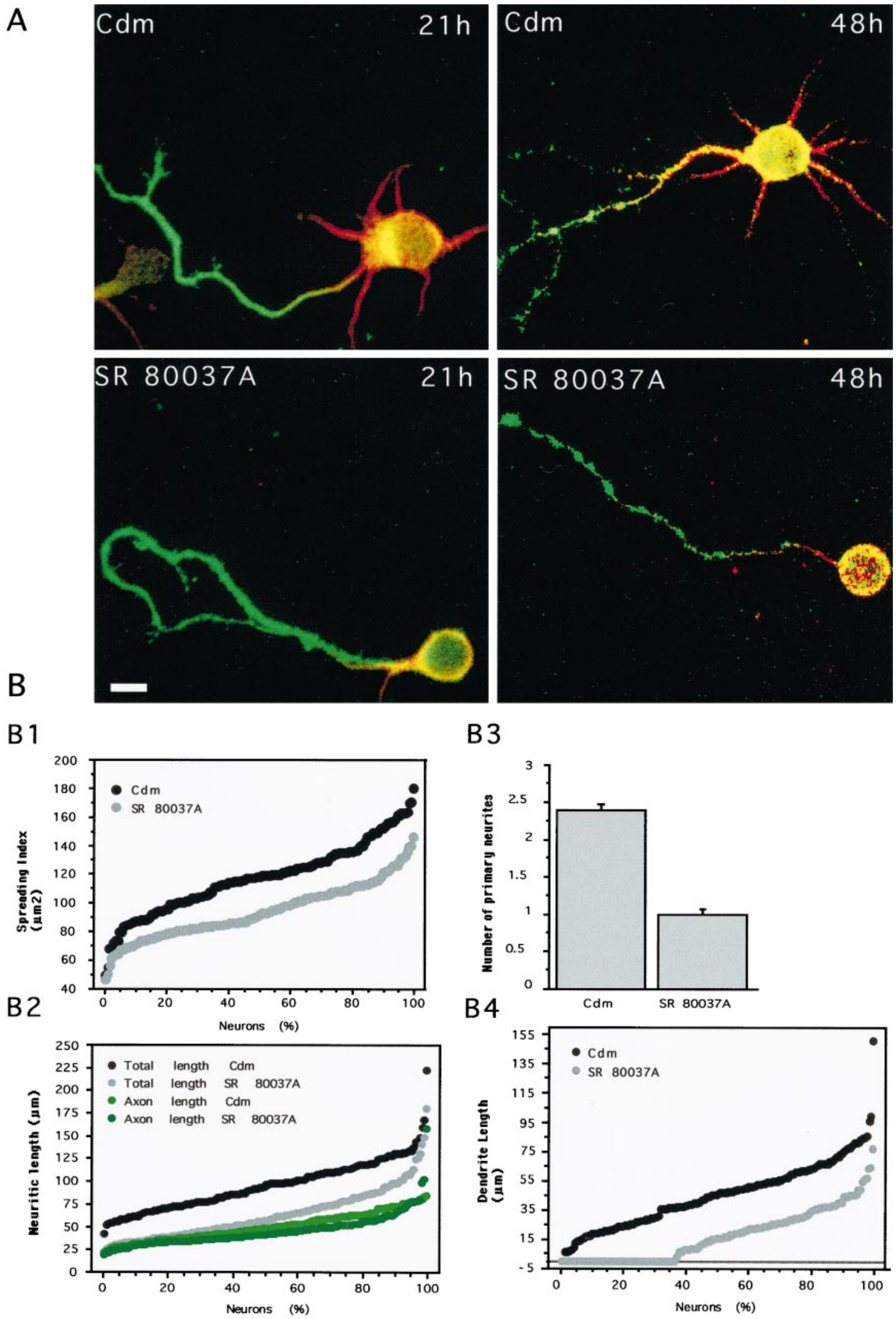

B3
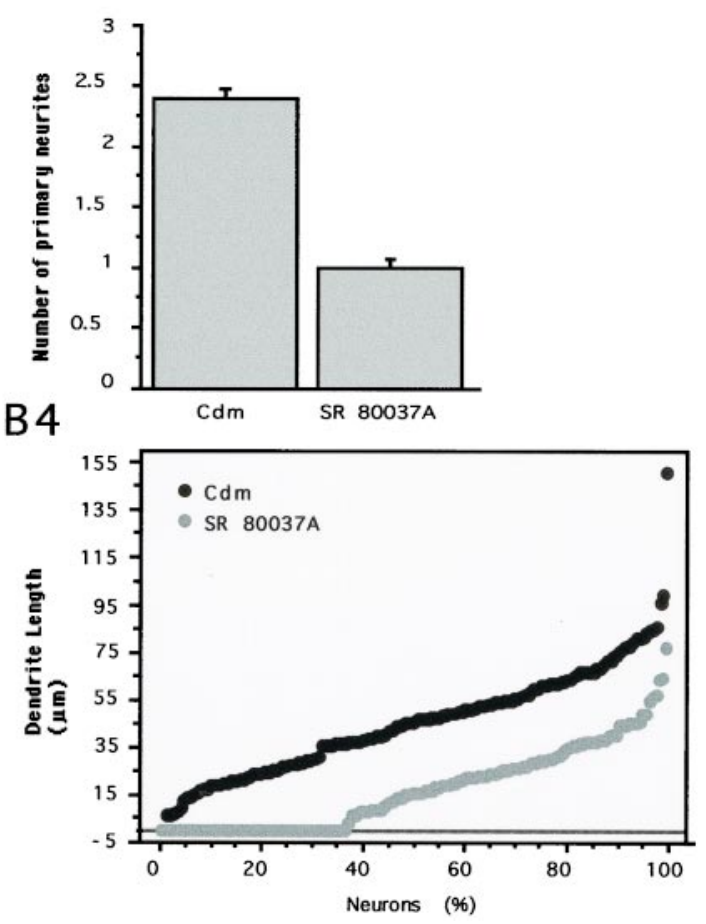

Figure 1. Effects of Heparan sulfate on neuronal morphology. A, E16 rat cortical neurons incubated $21 \mathrm{hr}$ (left) or $48 \mathrm{hr}$ (right) with (SR $80037 \mathrm{~A})$ or without $(\mathrm{Cdm}) 10 \mu \mathrm{g} / \mathrm{ml} \mathrm{SR} \mathrm{80037A} \mathrm{were} \mathrm{fixed} \mathrm{and} \mathrm{double-immunostained} \mathrm{for} \mathrm{MAP2} \mathrm{(red)} \mathrm{and} \tau$ (green). B, Morphometric analysis was performed on 50 neurons per condition ( $21 \mathrm{hr}$ with or without SR 80037A). Cumulative distributions of the neurons according to spreading index (B1), total neurite length or axonal length (B2), and dendrite length (B4) demonstrate a specific effect of SR 80037A on cell spreading and dendrite growth. This effect is parallel to a clear reduction in the number of primary neurites (B3). SR 80037A differs significantly from Cdm for all parameters $(p<0.001)$, except axonal length. 
Table 1. Presentations of morphological parameters investigated in Figures 1-5, 8, and 9

\begin{tabular}{|c|c|c|c|c|}
\hline & & $\begin{array}{l}\text { Primary } \\
\text { neurites }\end{array}$ & $\begin{array}{l}\text { Dendrite } \\
\text { length }(\mu \mathrm{m})\end{array}$ & $\begin{array}{l}\text { Axon length } \\
(\mu \mathrm{m})\end{array}$ \\
\hline \multirow[t]{2}{*}{ Figure 1} & $\mathrm{Cdm}$ & $2.4 \pm 0.065$ & $45.2 \pm 1.8$ & $50 \pm 1.2$ \\
\hline & SR 80037A & $0.99 \pm 0.075^{*}$ & $17.4 \pm 1.4^{*}$ & $45.4 \pm 1.4^{* *}$ \\
\hline \multirow[t]{3}{*}{ Figure 2} & $\mathrm{Cdm}$ & $3.5 \pm 0.15$ & $64.0 \pm 4.0$ & $48.9 \pm 2.7$ \\
\hline & SR 80037A & $2 \pm 0.18^{*}$ & $34.5 \pm 3.7^{*}$ & $70.5 \pm 4.0^{*}$ \\
\hline & SR 80037A-FITC & $2 \pm 0.15^{*}$ & $34.7 \pm 3.0^{*}$ & $57.8 \pm 3.5$ \\
\hline \multirow[t]{4}{*}{ Figure $3 B$} & $\mathrm{Cdm}$ & $2.6 \pm 0.11$ & $55 \pm 3.8$ & $66.4 \pm 3.8$ \\
\hline & SR 80037A & $1.7 \pm 0.12^{*}$ & $34.3 \pm 4.6^{* *}$ & $92.6 \pm 6^{*}$ \\
\hline & Chx & $2.6 \pm 0.13$ & $52.6 \pm 4.7$ & $58.2 \pm 3.3$ \\
\hline & Chx + SR 80037A & $1.7 \pm 0.15^{*}$ & $48.2 \pm 3.6$ & $74.5 \pm 5^{*}$ \\
\hline \multirow[t]{4}{*}{ Figure $4 A$} & $\mathrm{Cdm}$ & $2.8 \pm 0.17$ & $62.9 \pm 3.7$ & $49.6 \pm 2.8$ \\
\hline & SR 80037A & $1.6 \pm 0.16^{*}$ & $34 \pm 4.5^{*}$ & $62.9 \pm 4.4$ \\
\hline & EGFR1068Y-P & $2.5 \pm 0.18$ & $56.8 \pm 4.4$ & $45.5 \pm 2.3$ \\
\hline & EGFR1068Y-P/SR 80037A & $1.6 \pm 0.2$ & $54.5 \pm 2.8$ & $63.4 \pm 3.7^{* *}$ \\
\hline \multirow[t]{2}{*}{ Figure $4 B$} & $\mathrm{Cdm}$ & $2.9 \pm 0.13$ & $49.9 \pm 3.9$ & $28 \pm 0.8$ \\
\hline & SR 80037A & $1.2 \pm 0.1^{*}$ & $20.2 \pm 1.9^{*}$ & $28.7 \pm 0.9$ \\
\hline \multirow[t]{4}{*}{ Figure $4 C$} & $\mathrm{Cdm}$ & $2.3 \pm 0.08$ & $50.5 \pm 2.3$ & $60.8 \pm 2.4$ \\
\hline & SR 80037A & $1.4 \pm 0.08^{*}$ & $30.8 \pm 2.4^{*}$ & $51.3 \pm 2.6$ \\
\hline & PTX & $1.9 \pm 0.8$ & $42.7 \pm 2$ & $51.6 \pm 2.2$ \\
\hline & PTX + SR 80037A & $2 \pm 0.1$ & $42.9 \pm 2.8$ & $55 \pm 3.2$ \\
\hline \multirow[t]{4}{*}{ Figure $5 A$} & $\mathrm{Cdm}$ & $3.4 \pm 0.16$ & $65.2 \pm 3.6$ & $62.9 \pm 3.9$ \\
\hline & SR 80037A & $2.1 \pm 0.18^{*}$ & $42.2 \pm 3.8^{* *}$ & $72.6 \pm 5.3$ \\
\hline & V-PKCi & $3.2 \pm 0.15$ & $56.6 \pm 5.2$ & $55.1 \pm 2.3$ \\
\hline & V-PKCi/SR 80037A & $3.3 \pm 0.19$ & $70.8 \pm 5.6$ & $58 \pm 4$ \\
\hline \multirow[t]{3}{*}{ Figure 8} & $\mathrm{Cdm}$ & $2.7 \pm 0.09$ & $58.4 \pm 2.4$ & $55.8 \pm 2.3$ \\
\hline & SR 80037A & $2.1 \pm 0.09^{*}$ & $45.5 \pm 2^{*}$ & $63.2 \pm 2.3$ \\
\hline & $\mathrm{C} 3$ toxin & $2 \pm 0.08^{*}$ & $41.0 \pm 2.3^{*}$ & $68.4 \pm 2.3$ \\
\hline \multirow[t]{3}{*}{ Figure 9} & $\mathrm{Cdm}$ & $3 \pm 0.14$ & $59.3 \pm 3.1$ & $69.1 \pm 5.6$ \\
\hline & SR 80037A & $1.7 \pm 0.09^{*}$ & $43.7 \pm 3.6^{* *}$ & $95.3 \pm 3.7^{*}$ \\
\hline & DSbm & $2.4 \pm 0.13^{* *}$ & $70.7 \pm 3.7$ & $65.9 \pm 3.7$ \\
\hline
\end{tabular}

Figure 1: Cdm versus SR 80037A; Figure 2: Cdm versus SR 80037A, Cdm versus SR 80037A-FITC; Figure 3: Cdm versus SR 80037A, CHX versus CHX-SR80037A; Figure 4A: Cdm versus SR 80037A, EGF versus EGF-SR80037A; Figure 4B: Cdm versus SR 80037A; Figure 4C: Cdm versus SR 80037A, PTX versus PTX-SR 80037A; Figure 5A: Cdm versus SR 80037A, V-PKCi versus V-PKCi-SR 80037A; Figure 8: Cdm versus SR 80037A, Cdm versus C3; Figure 9: Cdm versus SR $80037 \mathrm{~A}, \mathrm{Cdm}$ versus DSbm.

$* p<0.0005$.

$* * p<0.05$.

in the somatodendritic compartment, does not respond to a DS GAG that does not block dendrite growth.

\section{MATERIALS AND METHODS}

Cortical neuron cultures. Pure neuronal cultures were prepared according to Lafont et al. (1994). In brief, dissociated cortical cells from 16-d-old [embryonic day 16 (E16)] rat embryos (IFFA Credo, France) or from transgenic mice were seeded on polyornithin-coated ( $40 \mathrm{kDa}$, Sigma, St. Louis, MO) $16-\mathrm{mm}$-diameter culture wells $(1.5 \mu \mathrm{g} / \mathrm{ml})$ or glass coverslips $(15 \mu \mathrm{g} / \mathrm{ml})$ at a density of $25 \times 10^{3}$ cells $/ \mathrm{cm}^{2}$ (immunocytochemistry) or $12 \times 10^{3} \mathrm{cells} / \mathrm{cm}^{2}$ (morphological analysis). Chemically defined medium (Cdm) consisted of DMEM-F-12 (1:1, Life Technologies, Gaithersburg, MD) complemented with a mixture of hormones, proteins, and salts (Rousselet et al., 1988). Peptides (concentrations indicated in the text), cycloheximide $(1 \mu \mathrm{M})$, or GAGs [SR 80037A, SR 80037A-FITC, dermatan sulfate from bovine mucosa (DSbm, Sigma) at a concentration of 10 $\mu \mathrm{g} / \mathrm{ml}]$ were added $30 \mathrm{~min}$ after seeding. SR 80037A was prepared as described earlier (Petitou et al., 1992; Petitou and van Boeckel, 1993). Collagen from one rat tail was removed sterilely, dissolved overnight at $4^{\circ} \mathrm{C}$ in $100 \mathrm{ml}$ of acetic acid $(0.1 \%)$, centrifuged at low speed, and dialyzed against $2 \times 10$ volumes of DMEM 1:10 adjusted to $\mathrm{pH} 4$ with $\mathrm{HCl}$. Collagen gels were obtained by adding $75 \%$ rat tail collagen to the culture medium (in replacement of water) and by adjusting the $\mathrm{pH}$ to 7.2 with $\mathrm{NaOH}$.

Immunocytochemistry. Cells fixed for $20 \mathrm{~min}$ at room temperature
(RT) with $4 \%$ paraformaldehyde (PAF) in PBS were permeabilized in $0.1 \%$ Triton $\mathrm{X}-100$ for $5 \mathrm{~min}$, incubated $\left(1 \mathrm{hr}, 37^{\circ} \mathrm{C}\right)$ with polyclonal anti-MAP2 antibody (1:400, gift of Dr. A. Fellous), washed three times, and further incubated for $1 \mathrm{hr}$ at $37^{\circ} \mathrm{C}$ with monoclonal anti- $\tau$ antibody (1:50, Boerhinger Mannheim, Indianapolis, IN). After three washes, cells were incubated $\left(1 \mathrm{hr}, 37^{\circ} \mathrm{C}\right)$ with CY3-conjugated anti-rabbit Igs (1:200), washed three times, incubated $\left(1 \mathrm{hr}, 37^{\circ} \mathrm{C}\right)$ with biotinylated anti-mouse Igs $(1: 200)$, washed three times, incubated $\left(1 \mathrm{hr}, 37^{\circ} \mathrm{C}\right)$ with FITC-conjugated streptavidin (1:200), washed three times in PBS and once in water, and mounted in Vectashield. All dilutions and washes were in PBS, and all incubations were in PBS plus $10 \%$ fetal calf serum. Immunocytochemical staining of E16 rat embryo cortical explants cultured in collagen gels was achieved as above but with longer incubation periods. Cells and explants were observed on an inverted fluorescence microscope (Leitz) or a confocal microscope (Zeiss, Molecular Dynamics system).

Morphological analysis. Cells fixed with PAF for $20 \mathrm{~min}$ at RT were washed in PBS, stained with toluidine blue $\left(0.2 \%\right.$ in $\left.1 \% \mathrm{Na}_{2} \mathrm{CO}_{3}\right)$, rinsed in water, and air-dried. Each experiment was done three times. Fifty to 100 neurons per condition were digitalized and analyzed with morphological analysis software (Neurolab France). Scheffe's test (5\%) was used to determine whether treated and control cells were statistically different. A one-tailed $p$ value $<0.05$ was considered significant.

Preparation of plasma membranes. Cortical tissues (E16 rat embryos) homogenized with a Dounce homogenizer (10 strokes) were passaged 

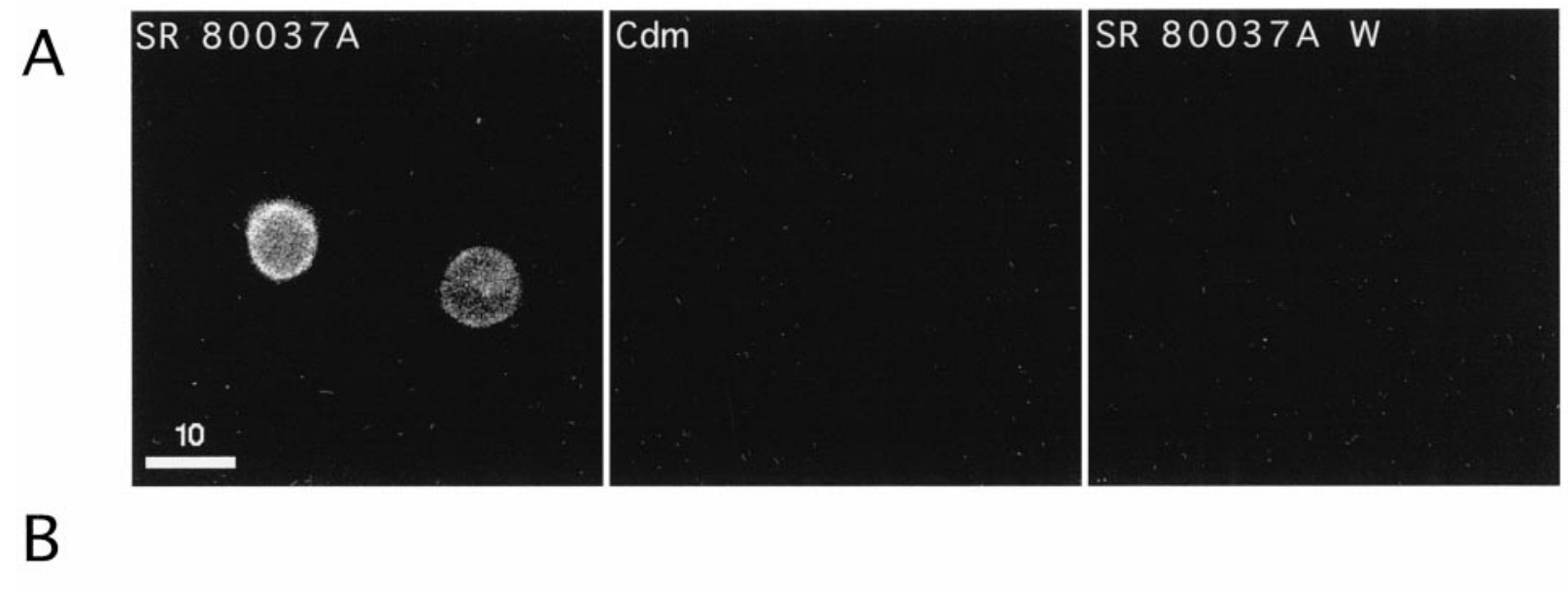

B
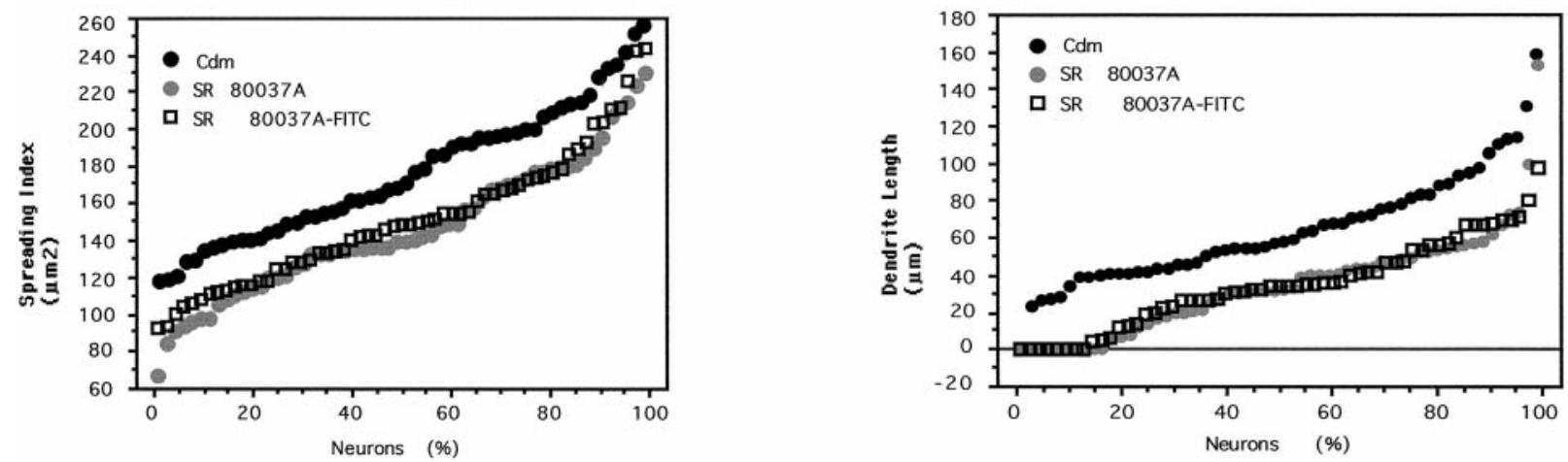

Figure 2. One hour of exposure to SR 80037A induces the phenotype. $A$, E16 cortical cells were incubated with SR $80037 \mathrm{~A}-\mathrm{FITC}(10 \mu \mathrm{g} / \mathrm{ml})$ for $1 \mathrm{hr}$, briefly washed (SR 80037A W, third panel) or not (SR 80037A, first panel) with $0.5 \mathrm{M} \mathrm{NaCl}$, fixed, and analyzed by confocal microscopy. SR $80037 \mathrm{~A}$ accumulation at the cell surface (bright rim) was lost after washing (compare with control cells not incubated with SR 80037A-FITC, second panel). B, E16 cortical cells were treated with $10 \mu \mathrm{g} / \mathrm{ml} \mathrm{SR} \mathrm{80037A} \mathrm{or} \mathrm{SR} \mathrm{80037A-FITC} \mathrm{for} 1 \mathrm{hr}$, washed with $0.5 \mathrm{~m} \mathrm{NaCl}$, and let to differentiate for $21 \mathrm{hr}$ in Cdm (without $\mathrm{NaCl}$ ). Cumulative distributions of the neurons according to spreading index (left) and dendrite length (right) demonstrate that SR 80037A-FITC is as active as SR 80037A and that the two aspects of the phenotype are induced within $1 \mathrm{hr}$ of SR 80037A presentation. $p<0.0001$ for SR 80037A versus Cdm (spreading index); $p<0.002$ for SR 80037A-FITC versus Cdm (spreading index). For all other parameters, see statistics in Table 1 .

(three times) through a 26 gauge needle in cold buffer A (10 mM Tris, $\mathrm{pH}$ 7.4, $100 \mu \mathrm{M}$ EDTA, and $0.25 \mathrm{~m}$ sucrose) plus protease inhibitors $(1 \mathrm{~mm}$ Pefablock, $1 \mu \mathrm{M}$ leupeptin, $1 \mu \mathrm{M}$ pepstatin, and $0.3 \mu \mathrm{M}$ aprotinin). The homogenate was loaded on sucrose (1.7 $\mathrm{M}$ in buffer $\mathrm{A})$ and centrifuged $\left(150,000 \times g, 30 \mathrm{~min}, 4^{\circ} \mathrm{C}\right)$ in an SW41 rotor $($ Beckman $)$. The membranes collected at the $1.7 \mathrm{M} / 0.25 \mathrm{M}$ interface were loaded on a second $1.7 \mathrm{M}$ sucrose cushion, centrifuged $\left(150,000 \times g, 30 \mathrm{~min}, 4^{\circ} \mathrm{C}\right)$, collected, resuspended in $10 \mathrm{~mm}$ Tris, pH 7.4, $100 \mu \mathrm{M}$ EDTA, and $0.25 \mathrm{M}$ sucrose, pelleted $\left(15,000 \times g, 15 \mathrm{~min}, 4^{\circ} \mathrm{C}\right)$, and resuspended in buffer A plus protease inhibitors. In the case of explant cultures, before membrane preparation (as above), the somatodendritic and axonal regions of the explant were cut off the gel, and the axons were rid of collagen by a brief incubation $\left(10 \mu \mathrm{g} / \mathrm{ml}, 30 \mathrm{~min}\right.$ at $\left.37^{\circ} \mathrm{C}\right)$ with collagenase (Sigma). ADP ribosylation of axonal and dendritic membranes was performed as indicated below using $10 \mu \mathrm{g}$ of proteins. Proteins were quantified using the micro BCA protein assay reagent kit (Pierce, Rockford, IL).

$A D P$ ribosylation. ADP ribosylation with pertussis toxin (PTX, Sigma) or C3 (a kind gift of Dr. P. Boquet) was carried out according to Brabet et al. (1990). The membranes (23-30 $\mu \mathrm{g})$ were preincubated for 1, 15, or $30 \mathrm{~min}$ with or without SR $80037 \mathrm{~A}$ (or DSbm) at $37^{\circ} \mathrm{C}$, in (in $\mathrm{mm}$ ) 70 Tris-HCl, pH 7.5, 25 dithiothreitol, 20\% glycerol, 1 EDTA, $0.1 \mathrm{MgCl}_{2}$, 1 ATP, 100 thymidine, and 10 nicotinamide. Incubation was in a final volume of $100 \mu \mathrm{l}$ for $1 \mathrm{hr}$ at $37^{\circ} \mathrm{C}$, with $0.5 \mu \mathrm{M}$ nicotinamide adenine dinucleotide (NAD), $1 \mu \mathrm{Ci}{ }^{32} \mathrm{P}-\mathrm{NAD}$ (DuPont NEN, Boston, MA) and PTX $(2.5 \mu \mathrm{g})$ or C3 (the appropriate dilution of C3 was established for each batch of enzyme). Samples precipitated in 10\% TCA were separated by SDS-PAGE and analyzed by phosphoimaging (Fuji).

Immunoprecipitation. ADP-ribosylated membranes were boiled for 5 min in $10 \%$ SDS, and four volumes of $190 \mathrm{~mm} \mathrm{NaCl}, 50 \mathrm{~mm}$ Tris, $\mathrm{pH} 7.4$,
6 mm EDTA, and $2.5 \%$ Triton X-100 were added. After 30 min on ice the samples were centrifuged $\left(10,000 \mathrm{rpm}, 5 \mathrm{~min}, 4^{\circ} \mathrm{C}\right)$. Supernatants were added to $50 \mu$ l of protein-A-Sepharose (in buffer A) previously incubated (or not) with the appropriate anti- $\mathrm{G}_{\alpha \mathrm{i}}$ or $-\mathrm{G}_{\alpha \mathrm{o}}$ antibody and incubated for $1 \mathrm{hr}$ at $37^{\circ} \mathrm{C}$. After centrifugation $\left(14,000 \mathrm{rpm}, 10 \mathrm{~min}, 4^{\circ} \mathrm{C}\right)$, the pellets were washed five times in $150 \mathrm{~mm} \mathrm{NaCl}, 10 \mathrm{~mm}$ Tris, $\mathrm{pH} 7.4,5 \mathrm{~mm}$ EDTA, $0.05 \%$ SDS, and $0.1 \%$ Triton $\mathrm{X}-100$, and once in $150 \mathrm{~mm} \mathrm{NaCl}$, $10 \mathrm{~mm}$ Tris, $\mathrm{pH}$ 7.4, and $5 \mathrm{~mm}$ EDTA. The pellets were resuspended in Laemmli buffer, heated for $5 \mathrm{~min}$ at $100^{\circ} \mathrm{C}$ and centrif uged $(14,000 \mathrm{rpm}$, $10 \mathrm{~min}, \mathrm{RT}$ ). Supernatants were analyzed by SDS-PAGE. Affinitypurified antibodies against $C$-terminal decapeptides of $G_{\alpha \mathrm{o}}$ and $G_{\alpha i-3}$ (which also recognizes the $\mathrm{C}$-terminal domains of $\mathrm{G}_{\alpha \mathrm{i} 1}$ and $\mathrm{G}_{\alpha \mathrm{i} 2}$ ) were from Santa Cruz Biotechnology, Santa Cruz, CA.

Western blot analysis. Membranes from E16 rat cortices were prepared as indicated above, and the proteins separated by SDS-PAGE were transferred on Immobilon. Filters were incubated with anti- $\rho$ (SantaCruz, 1:100), anti- $\mathrm{G}_{\alpha \mathrm{o}}(1: 1000)$, or anti- $\mathrm{G}_{\alpha \mathrm{i}-3}(1: 1000)$ overnight at $4^{\circ} \mathrm{C}$, washed, further incubated for $2 \mathrm{hr}$ at RT with peroxidase-conjugated anti-rabbit whole antibody, washed, and revealed with ECL (Amersham, Arlington Heights, IL).

Two-dimensional gel electrophoresis. ADP-ribosylated samples were lyophilized and resuspended in $20 \mu \mathrm{l}$ of $9.5 \mathrm{M}$ urea, $10 \% \mathrm{NP}-40,5 \%$ $\beta$-mercaptoethanol, $1.6 \%$ biolyte 5:7 (Bio-Rad, Hercules, CA), 0.4\% biolyte 3:10 (Bio-Rad) and mixed with $20 \mu \mathrm{l}$ of $9 \mathrm{M}$ urea, $0.8 \%$ biolyte $5: 7$, $0.2 \%$ biolyte $3: 10$, and $0.0025 \%$ bromophenol blue. First dimension was in $9.2 \mathrm{M}$ urea, $4 \%$ acrylamide, $2 \% \mathrm{NP}-40,1.6 \%$ Biolyte $5: 7$, and $0.4 \%$ biolyte $3: 10$. Second dimension was achieved on a 7-18\% acrylamide gradient (SDS-PAGE). 

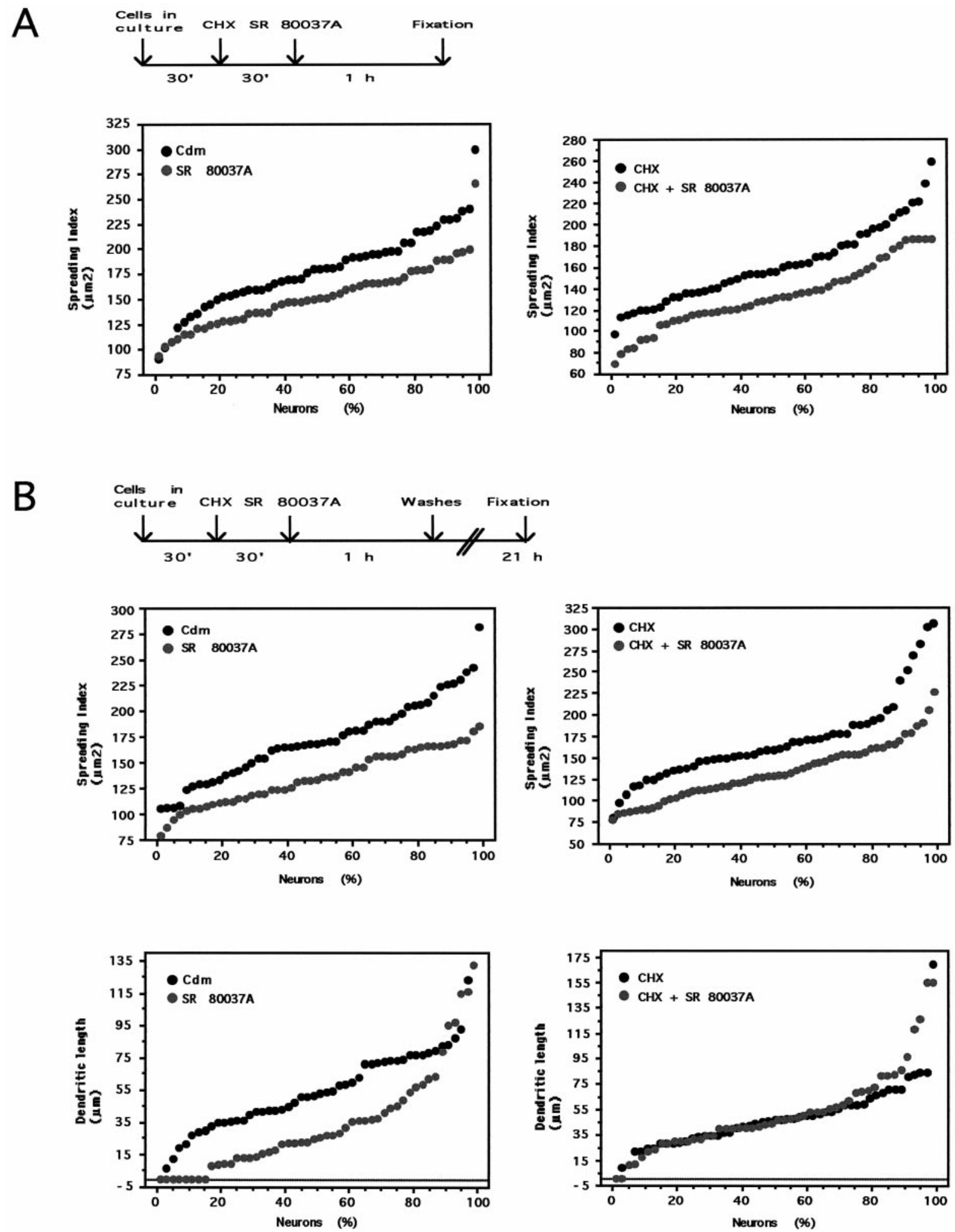

Figure 3. Effect of protein synthesis inhibition on early and late phenotypes. $A$, E16 cortical neurons treated for $1 \mathrm{hr}$ with SR $80037 \mathrm{~A}$ in the presence of cycloheximide $(\mathrm{CHX})$ at $1 \mu \mathrm{M}$ (scheme) and fixed still adopt the rounded phenotype. The left panel is without $\mathrm{CHX}$ (for control). $p<0.0001$ (CHX vs CHX-SR 80037A and control vs SR 80037A). B, Cycloheximide was removed at the same time as SR 80037A, allowing protein synthesis to resume rapidly (scheme), and the cells were allowed to grow for another $19 \mathrm{hr}$. The left panel is without CHX (for control). The decrease in cell spreading was preserved ( $p<0.0001$; CHX vs CHX-SR 80037A), but the effect on dendrite length was lost $(p<1.0$ CHX vs CHX-SR 80037A). For other parameters, see Table 1. 


\begin{tabular}{|c|c|c|c|}
\hline Drugs & Targets & Soma & $\begin{array}{l}\text { Dendrite } \\
\text { length }\end{array}$ \\
\hline Genestein & Tyrosine kinase $\mathrm{R}$ & No & No \\
\hline EGFR $^{1068}$ Y-P & $\begin{array}{l}\text { SH2 domain of Grb2 } \\
\text { (Williams et al., 1997; } \\
\text { Fig. 4) }\end{array}$ & No & No \\
\hline FGFR $^{766} \mathrm{Y}-\mathrm{P}$ & $\begin{array}{l}\text { SH2 domain of the } \text { PLC }_{\gamma} \\
\text { (Hall et al., 1996) }\end{array}$ & No & No \\
\hline $\begin{array}{l}\text { Transgenic FGF-R1 } \\
\text { animals }\end{array}$ & FGF-R (Fig. 4) & No & No \\
\hline $\begin{array}{l}\text { Pertussis toxin } \\
\quad(\mathrm{PTX})\end{array}$ & $\mathrm{G}_{\mathrm{i}}$ and $\mathrm{G}_{\mathrm{o}}$ (Fig. 4) & Yes & Yes \\
\hline V-PKCi peptide & $\begin{array}{l}\text { PKC (PKN) (Theodore } \\
\text { et al., 1995; Fig. 5) }\end{array}$ & Yes & Yes \\
\hline Staurosporine & $\mathrm{PKC} / \mathrm{PKN}$ & Yes & Yes \\
\hline
\end{tabular}

This table summarizes the results obtained with SR 80037A and various compounds (genestein at $100 \mu \mathrm{M}, \mathrm{EGF}^{1068} \mathrm{Y}-\mathrm{P}$ at $5 \mu \mathrm{g} / \mathrm{ml}$, FGFR ${ }^{766} \mathrm{Y}-\mathrm{P}$ at $1 \mu \mathrm{g} / \mathrm{ml}, \mathrm{PTX}$ at 0.5 $\mu \mathrm{g} / \mathrm{ml}, \mathrm{V}-\mathrm{PKCi}$ at $0.5 \mu \mathrm{M}$, and staurosporine at $0.1 \mu \mathrm{M})$. No and Yes mean no inhibition or inhibition, respectively, of SR 80037A effect on soma spreading and dendrite elongation.

\section{RESULTS}

\section{SR 80037A decreases cell spreading and inhibits dendrite outgrowth}

Figure $1 A$ illustrates the influence of SR $80037 \mathrm{~A}$ on the shape and polarity of E16 rat cortical neurons 21 and $48 \mathrm{hr}$ after seeding. In control conditions $(\mathrm{Cdm})$, neurons exhibit a clear polarized phenotype with several MAP2-positive short extensions and a long $\tau$-positive neurite. This specific distribution of the axonal $(\tau)$ and dendritic (MAP2) markers (for review, see Craig and Banker, 1994) is already present after $21 \mathrm{hr}$ and allowed us to establish that, in our culture conditions, the longest neurite is always the axon. Figure $1 A$ also illustrates that SR 80037A decreases the apparent diameter of the soma and the number of primary dendrites. This is quantified in Figure $1 B$ and Table 1; in the presence of SR 80037A the mean number of primary neurites, soma spreading index (in fact the maximal cross-sectional area, corresponding to the surface occupied by the soma on the culture dish after fixation), total neurite length, and dendrite length decrease significantly, whereas axonal length is not modified. The main effect of SR 80037A is, thus, an inhibition of soma spreading and of dendrite initiation and elongation.

In all experiments presented in this study, axonal length was either increased or not modified after SR 80037A addition, whereas the number of primary neurites and dendrite development were always reduced. Soma spreading estimated by spreading index was also often reduced by the addition of SR 80037A. For each experiment, results concerning the number of primary neurites, dendrite length, and axonal length are presented in Table 1. Finally, the same effect on cell rounding and dendrite elongation was observed for rat or mouse neurons from all tested brain regions (cerebellum, spinal cord, and cortex; data not shown).

\section{One hour exposure to SR 80037 A is sufficient to induce cell response}

SR $80037 \mathrm{~A}$, added to neurons for $1 \mathrm{hr}$, was washed by a brief rinse in $\mathrm{Cdm}$ supplemented with $0.5 \mathrm{~m} \mathrm{NaCl}$. The medium was then changed for $\mathrm{Cdm}$, and the culture was pursued for an additional $19 \mathrm{hr}$ before morphological analysis. To verify that $\mathrm{NaCl}$ washing is efficient in removing the sugar, we used fluoresceinated SR 80037A (SR 80037A-FITC) (Lafont et al., 1994). Figure $2 A$ illustrates that all SR 80037A-FITC is removed by the brief $\mathrm{NaCl}$ rinse. Figure $2 B$ and Table 1 demonstrate that FITC conjugation does not modify the activity of the sugar and that only $1 \mathrm{hr}$ of incubation with SR 80037A or SR 80037A-FITC is sufficient to induce and maintain cell rounding and dendrite inhibition for at least $19 \mathrm{hr}$.

To evaluate the importance of protein synthesis in the induced phenotype, we used cycloheximide (CHX), a drug that specifically and reversibly blocks protein synthesis. CHX was added 30 min before SR 80037A. After $1 \mathrm{hr}$ exposure to SR 80037A, the cells were either fixed (Fig. $3 A$ ) or washed with $0.5 \mathrm{M} \mathrm{NaCl}$ to remove SR 80037A and CHX and let to differentiate in Cdm for $19 \mathrm{hr}$ (Fig. 3B). Cell body rounding occurs within $1 \mathrm{hr}$ (Fig. 3A) and in the absence of protein synthesis. When the cells were analyzed $19 \mathrm{hr}$ after removal of CHX and SR 80037A, the effects of the HS on cell rounding and on the number of primary neurites were maintained (Fig. 3B, Table 1), but the effect on total dendrite length was lost. Interestingly, axonal elongation was strongly stimulated, suggesting that the neurites (axons and dendrites) that are able to initiate despite the presence of SR 80037A grow at a very rapid pace after $\mathrm{CHX}$ and sugar removal. The same result was obstained if CHX was left for another $3 \mathrm{hr}$ after SR 80037A removal (data not shown).

\section{Analysis of SR 80037A signaling pathway}

To analyze the SR 80037A signaling pathway involved in the morphological phenotype we used the pharmacological reagents listed in Table 2. Many of these reagents are commercially available, e.g., staurosporin and PTX, but others have been developed in our laboratories (for review, see Derossi et al., 1998). The "homemade" dominant-negative inhibitors are peptides or phosphopeptides that act by interacting with active sites, as in the case of the PKC inhibitor (PKCi) (Derossi et al., 1998) or with the SH2 domain of PLC $\gamma$ or Grb2 (Hall et al., 1996; Williams et al., 1997). These peptides were made cell-permeable thanks to their linkage to another polypeptide (penetratin-1) that translocates across biological membranes and accumulates in the cytoplasm and nucleus of cells in culture (Derossi et al., 1994, 1996). Because the activity of cell-permeable peptides has been described earlier (Theodore et al., 1995; Hall et al., 1996; Williams et al., 1997), we simply summarized their effects in Table 2 . In the same table we report the use of neurons from a transgenic mouse expressing a truncated FGF receptor under the control of the neural specific enolase promoter. This truncated receptor behaves as a dominant negative membrane protein for all FGF receptors (Safell et al., 1997).

The results are summarized in Table 2 and are either not shown or quantified in Figures 4 and 5 and in Table 1. Because 1 $\mathrm{hr}$ exposure to SR 80037A was enough to induce the phenotype, chemical inhibitors were added for $30 \mathrm{~min}$ before SR 80037A, and the cells were further incubated for $1 \mathrm{hr}$ before replacement of SR 80037A and inhibitors with Cdm for $20 \mathrm{hr}$. In summary, of all tested compounds, the only active SR 80037A antagonists are pertussis toxin and PKC inhibitors. Figure $4 A$ and Table 1 illustrate the absence of inhibition of SR 80037A effects by a peptide that anatagonizes EGF signaling through Grb2. Figure $4 B$ and Table 1 demonstrate that neurons that do not respond to FGFs are still capable of responding to SR 80037A. In contrast, Figures $4 C$ and $5 A$ illustrate that PTX (Fig. $4 C$, Table 1) and penetratin1-PKCi (V-PKCi), the PKC peptidic inhibitor (Fig. 5A, Table 1), 

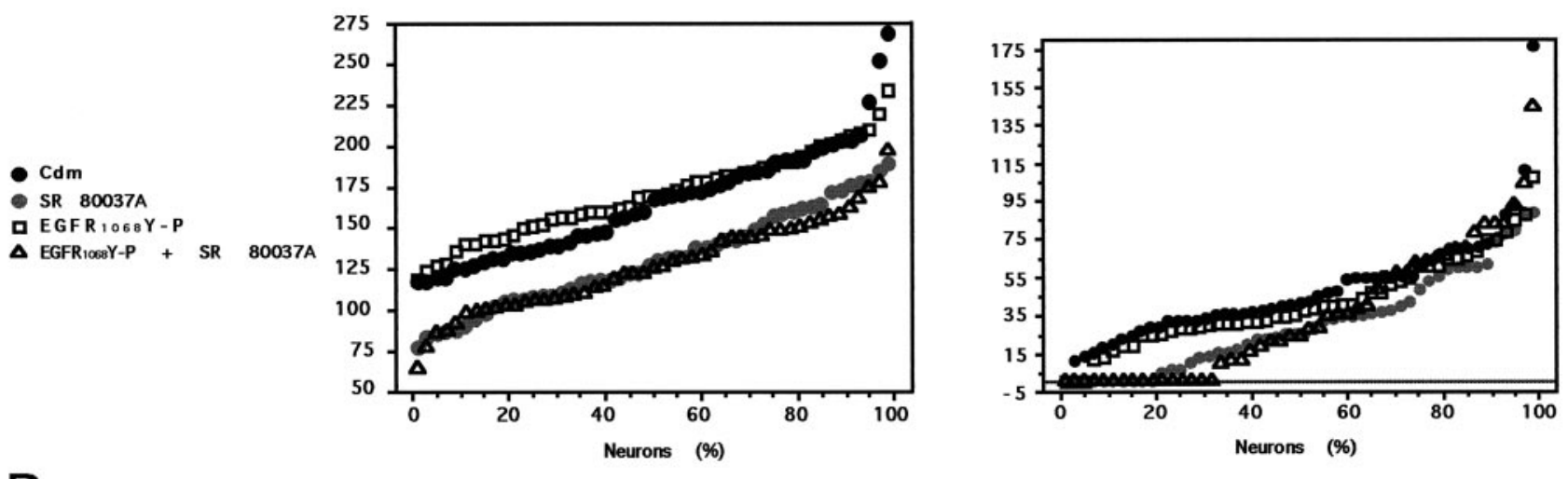

B

- $\mathrm{Cdm}$
- SR 80037A

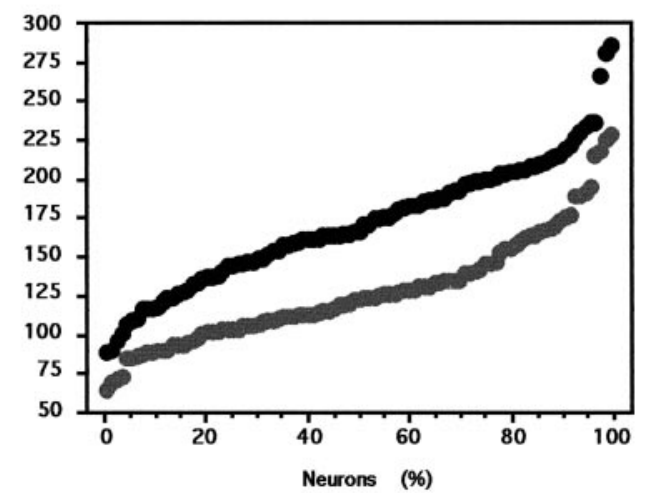

C
- Cdm

- SR 80037A

口 PTX

$\triangle$ PTX +SR 80037A

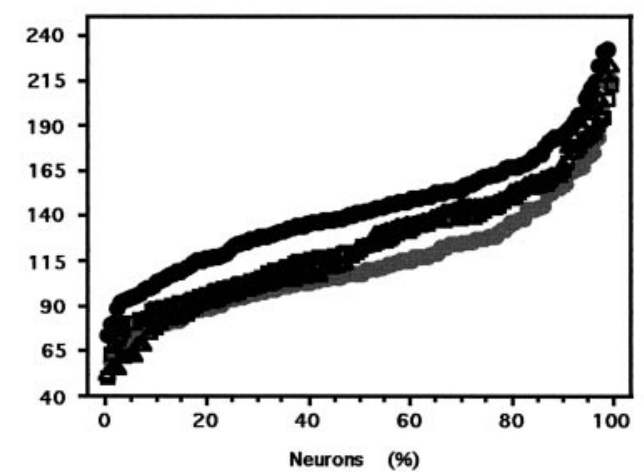

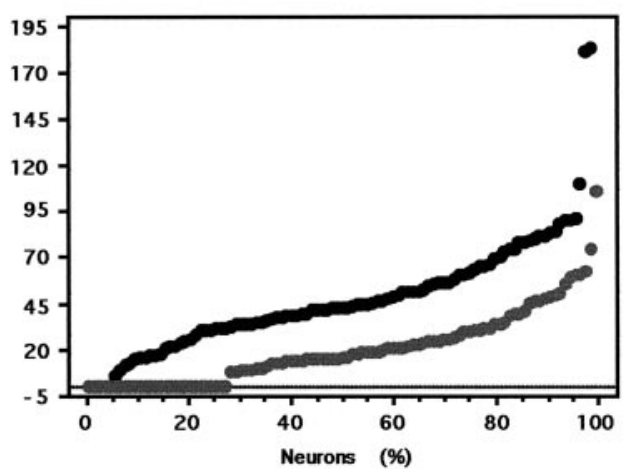

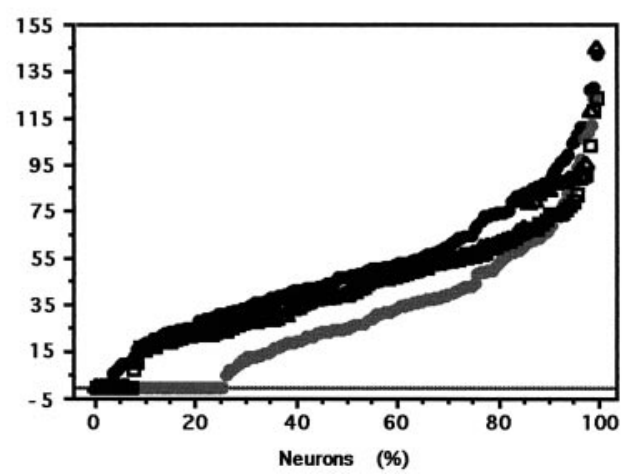

Figure 4. SR 80037A effects do not require active EGF and FGF receptors and are inhibited by pertussis toxin. Cumulative distributions according to spreading index and dendrite length of E16 rat $(A, C)$ and mouse $(B)$ neurons incubated with or without SR 80037A in different conditions. $A$, EGFR ${ }^{1068}$ Y-P does not affect SR 80037A activity. Spreading index and dendrite length are shown in the presence or absence of the inhibitor. $p<0.0001$, EGF ${ }^{1068}$ Y-P versus EGF ${ }^{1068}$ Y-P-SR 80037A (spreading index); $p<0.01$, EGF ${ }^{1068}$ Y-P versus EGF ${ }^{1068}$ Y-P-SR 80037A (dendrite length). For other parameters, see statistics in Table 1. B, Nonfunctional FGF receptors (neurons from transgenic embryos expressing a FGF-R1 dominant negative receptor) do not affect SR 80037A activity. $p<0.0001$ (spreading index and dendrite length, Cdm vs SR 80037A). C, PTX (0.5 $\mu \mathrm{g} / \mathrm{ml})$ added $30 \mathrm{~min}$ before SR 80037A and removed at the same time as SR 80037A (1 hr exposure to the sugar) inhibited both soma rounding and dendrite inhibition. Note that PTX has an effect per se on spreading index. $p<1.0$ (PTX vs PTX-SR 80037A, spreading index, and dendrite length). For all other parameters, see statistics in Table 1.

antagonize the effect of SR 80037A on neuronal spreading and dendrite growth. The inhibition of neuronal rounding is clear but partially masked by the per se effect of PTX and V-PKCi inhibitor on this parameter, even in the absence of SR 80037A. To validate the use of the V-PKCi we showed that stimulating the cells with PMA for $30 \mathrm{~min}$ before peptide addition antagonized its effect in a dose-dependent manner (Fig. 5B). Similar effects were obtained with the V-PKCi and staurosporine (data not shown). 
- Cdm

- SR 80037A

口 V-PKCi

$\Delta \mathrm{V}-\mathrm{PKCi}+$ SR 80037A
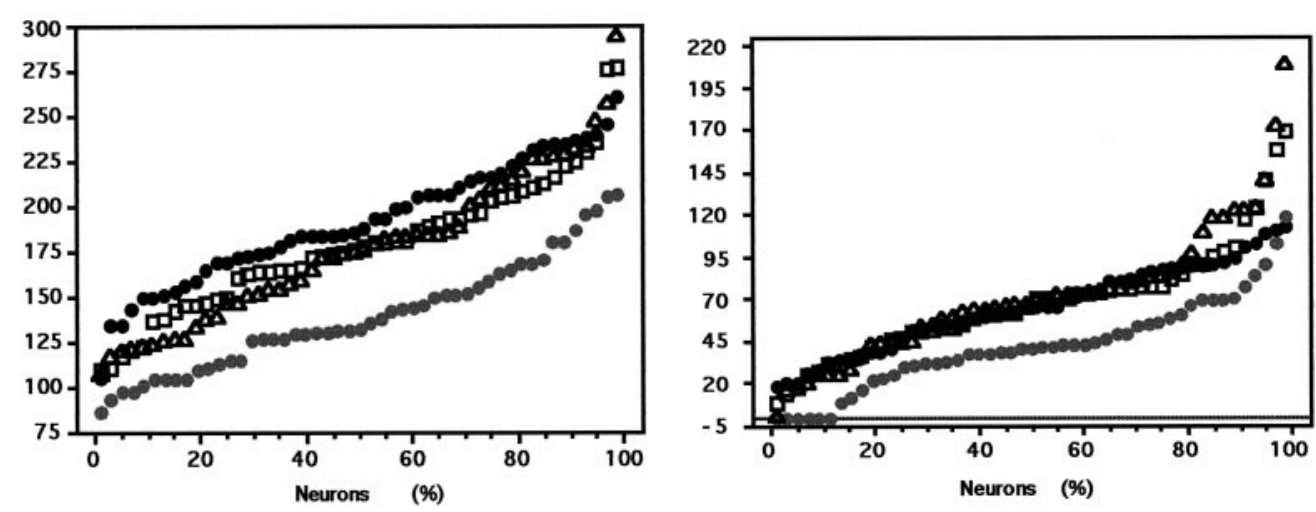

Dendrite length $(\mu \mathrm{m})$

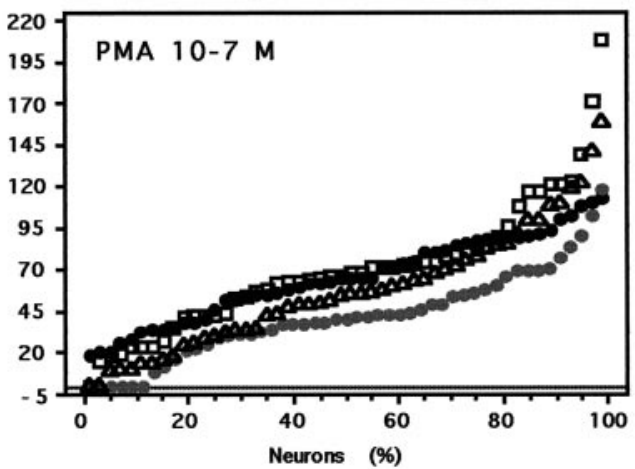

Figure 5. Protein kinase $\mathrm{C}$ is in the SR 80037A pathway. A, Cumulative distributions according to spreading index and dendrite length of E16 rat neurons incubated with or without SR 80037A (for $1 \mathrm{hr}$ ) with or without pretreatment with the cell-permeable PKC inhibitor (V-PKCi). V-PKCi inhibits both cell rounding and the effect on dendrite growth. $p<0.001$, Cdm versus SR 80037A (spreading); $p<0.01$, Cdm versus SR 80037A (dendrite growth); $p<1$, V-PKCi versus V-PKCi-SR 80037A (spreading); $p<0.6, \mathrm{~V}-\mathrm{PKCi}$ versus V-PKCi-SR 80037A (dendrite growth). For all other parameters, see statistics in Table 1. B, Treating the cells with PMA antagonizes the effect of V-PKCi in a dose-dependent manner. Inhibition is partial at $0.1 \mu \mathrm{M}$ (left panel) and total at $1 \mu \mathrm{M}$ PMA (right panel). This confirms that the effect of V-PKCi is through PKC inhibition. Left panel, $p<0.001, \mathrm{Cdm}$ versus SR 80037A (spreading); $p<0.008$, Cdm versus SR 80037A (dendrite length); $p<0.07$, V-PKCi-SR 80037A versus V-PKCi-SR 80037A-PMA 1 $\mu$ M (spreading); $p<0.2$, V-PKCi-SR 80037A versus V-PKCi-SR 80037A-PMA $1 \mu \mathrm{M}$ (dendrite length). Right panel, $p<0.0001$, Cdm versus SR 80037A (spreading and dendrite length); $p<0.004 \mathrm{~V}-\mathrm{PKCi}$-SR 80037A versus V-PKCi-SR 80037A-PMA $10 \mu \mathrm{M}$ (spreading); $p<0.006 \mathrm{~V}-\mathrm{PKCi}$-SR 80037A versus V-PKCi-SR 80037A-PMA $10 \mu \mathrm{M}$ (dendrite length).

\section{SR 80037 A activates Gi but inhibits Rho pathways}

PTX specifically incorporates ADP through ADP ribosylation of the $\mathrm{C}$-terminal domain of the $\alpha$ subunits of $\mathrm{G}_{\mathrm{o}}$ and $\mathrm{G}_{\mathrm{i}}$, two heterotrimeric GTPases (Neer et al., 1984). After heterotrimeric G-protein activation, the $\alpha$ subunits dissociate from the complex and become less accessible to PTX (Li, 1992). A decrease in ADP ribosylation provoked by a pharmacological agent therefore demonstrates that this agent is acting through a pathway involving either $G_{o}$ or $G_{i}$ activation. To verify that SR 80037A activity involves a heterotrimeric G-protein, membranes from the cortex of E16 rat embryos were incubated with the sugar, pelleted to remove the unbound ligand, and proceeded for ADP ribosylation of the G-proteins by PTX. As shown in Figure $6 A$ (top panel), SR 80037A inhibits the ADP ribosylation of a protein with an apparent molecular weight (MW) of $40 \mathrm{kDa}$. This inhibition was rapid and almost total after 30 min of incubation with the sugar (Fig. $6 A$, quantification in bottom panel). Western blot analysis of the membrane extracts demonstrates that $\mathrm{G}_{\mathrm{o} \alpha}$ and $\mathrm{G}_{\mathrm{i} \alpha}$ are expressed at this stage of development, with a larger amount of $\mathrm{G}_{\mathrm{i} \alpha}$ (prob- ably $\mathrm{G}_{\mathrm{i} \alpha 1}$ and $\mathrm{G}_{\mathrm{i} \alpha 2}$ because $\mathrm{G}_{\mathrm{i} \alpha 3}$ is not expressed in neurons; Fig. $6 B)$. The same Western blot demonstrates that the addition of SR 80037A does not modify the amount of G-protein present in the membranes and, therefore, that the effect of the sugar on the level of ADP ribosylation cannot be attributed to a degradation of the toxin substrates. Immunoprecipitations with anti- $\mathrm{G}_{\mathrm{o} \alpha}$ and anti$\mathrm{G}_{\mathrm{i} \alpha}$ antibodies (Fig. 6C) confirmed that SR 80037A inhibits PTXstimulated ADP ribosylation of both proteins and, thus, places the heterotrimeric $G$, in particular $G_{i}$, in the SR 80037A signaling pathway.

The activation of $\mathrm{G}_{\mathrm{i}}$ and the rapid and $\mathrm{CHX}$-resistant cell rounding that follows SR 80037A addition suggested a role for the actin cytoskeleton and, as a consequence, a possible involvement of $\rho$ GTPase (Machesky and Hall, 1996; Imamura et al., 1997; Hall, 1998). Therefore, we analyzed the effect of an exposure of the cortical membranes to SR 80037A on the ADP ribosylation of $\rho$ by $\mathrm{C} 3$, a $\rho$-specific toxin $(\mathrm{Li}, 1992)$. Figure $7 A$ illustrates and quantifies the kinetic of $\rho$ ADP ribosylation after exposure to SR 80037A and demonstrates that the sugar rapidly inhibits $\rho$ ADP 

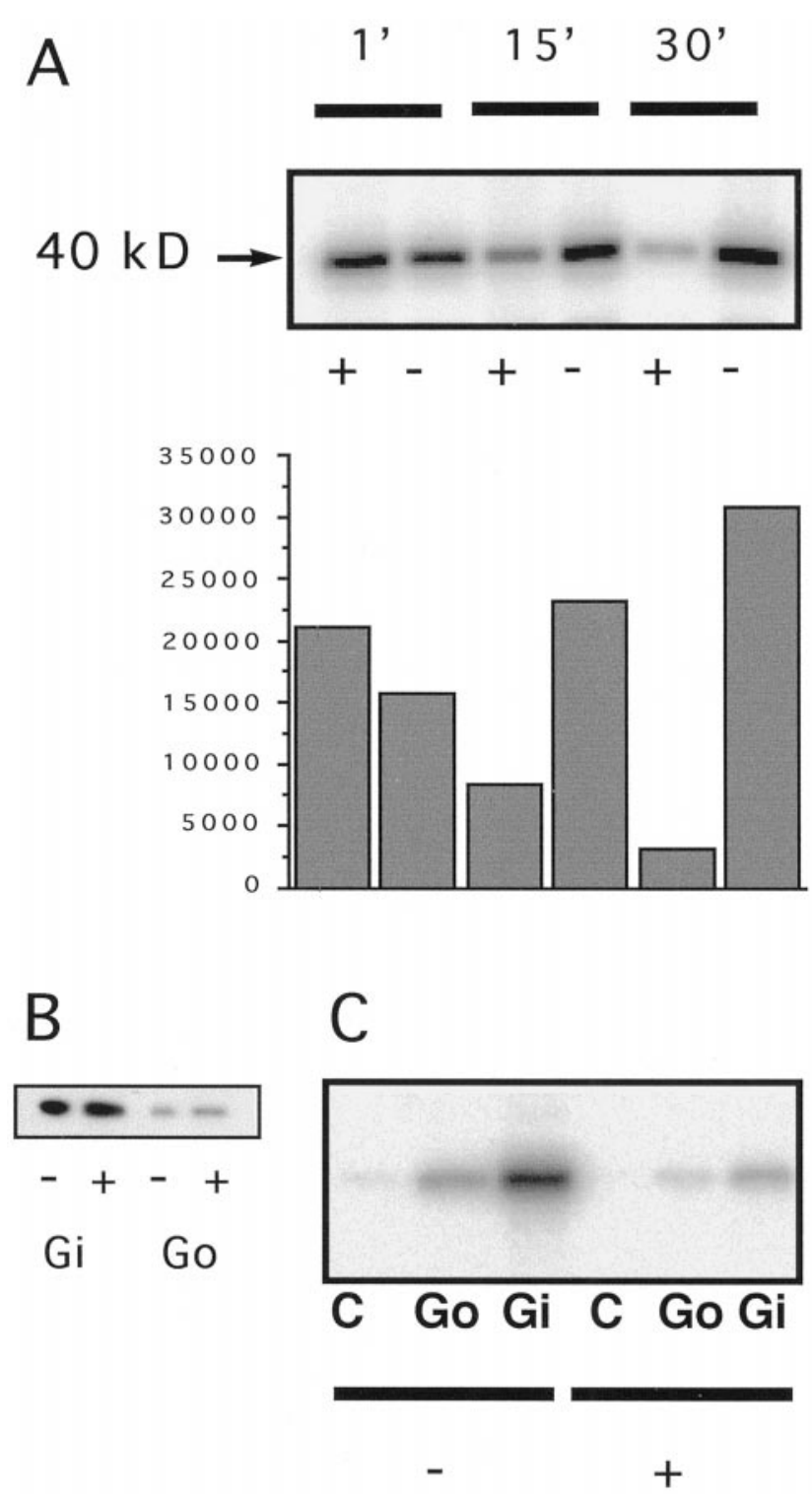

Figure 6. Heterotrimeric G-proteins are in the SR 80037A pathway. A, ADP ribosylation by PTX of a $40 \mathrm{kDa}$ protein in neuronal membranes pretreated with $(+)$ or without $(-)$ SR 80037 A during 1,15 , or 30 min and quantification by phosphoimager (bottom panel). This experiment is representative of three independent experiments in which SR 80037A reduced ADP ribosylation by 63,70 , and $90 \%$ after $30 \mathrm{~min}$. $B$, Western blot analysis of E16 cortical neurons using $G_{i \alpha}$ and $G_{o \alpha}$ antibodies. Incubation with SR 80037A (+) does not modify the membrane content in $G_{i}$ or $G_{o}$. $C$, Immunoprecipitation, with $\mathrm{G}_{\mathrm{i} \alpha}$ or $\mathrm{G}_{\mathrm{o} \alpha}$ antibodies, of ADP-ribosylated G-proteins from E16 neuronal membranes pretreated $(+)$ or not $(-)$ with SR 80037A.

ribosylation. Separation of the $\rho$ proteins by two-dimensional electrophoresis (Fig. 6B, top panel) further demonstrates that $\rho \mathrm{A}$ and $\rho \mathrm{C}$ but not $\rho \mathrm{B}$ are in the sugar-signaling pathway (Fig. $7 B$, quantification bottom panel). In the yeast, $\mathrm{PKC}$ is downstream of $\rho 1 p$ (Nonaka, 1995). Experiments demonstrating that staurosporine does not antagonize the effect of SR 80037A on the ADP ribosylation of $\rho$ by C3 (data not shown) also places PKC downstream of $\rho$ in the SR 80037A transduction pathway.

The decrease in $\rho$ ADP ribosylation suggests that the addition of SR 80037A decreases the accessibility of $\mathrm{Asn}^{41}$ (the ADP ribosylation site) to the toxin (Jalink et al., 1994), possibly by promoting an interaction of $\rho$ with a downstream partner. However, this does not say whether this partner inhibits or, on the contrary, enhances basal $\rho$ biological activity. To investigate this point we compared, in our biological model, the effect of SR 80037A with that of C3, a known inhibitor of $\rho$. As shown in Figure 8 and Table 1, C3 and SR 80037A have the same effects on cell spreading, the number of primary neurites and dendrite growth, and the same absence of effect on axonal elongation. This experiment, which reproduces the results of Threadgill et al. (1997), strongly suggests that SR 80037A provokes the association of $\rho$ with a downstream inhibitor.

\section{HS signaling pathway is primarily activated in the somatodendritic compartment and does not respond to DS}

We had shown previously that DSbm, a commercial dermatan sulfate from bovine mucosa, does not provoke cell rounding and does not decrease dendrite growth (Lafont et al., 1994; Fig. 9A, Table 1). Accordingly, DSbm does not displace radioactive SR 80037A from its binding sites at the neuronal surface (Lafont et al., 1994). We, thus, wanted to compare the respective effects of DSbm and SR 80037A on the ADP ribosylation of $\mathrm{G}_{\mathrm{i}}$ and $\rho$ in the axonal and somatodendritic compartments. To this end, small cortical explants were cultured in three-dimensional collagen gels, and the axons were allowed to invade the gels for 100-120 hr. Double staining of the explants with anti-MAP2 and anti- $\tau$ antibodies (Fig. 9B) illustrates that the axons (green) invade the collagen gel, whereas cell bodies and dendrites remain within the explant, with some axons. This experimental design permitted separation of the axonal and the somatodendritic compartments and preparation of the corresponding membranes. Figure $9 C$ illustrates that, for the same amount of protein, the somatodendritic compartment is highly enriched with $\mathrm{G}_{\mathrm{i}}$ and $\rho$ and that the addition of SR 80037A does not modify the amount of protein, for example, through proteolysis. Finally, Figure $9 D$ demonstrates that, for an equal amount of membrane proteins, the response to the addition of SR 80037A was much higher on membranes derived from the somatodendritic compartment, strongly suggesting a polarized distribution of the signaling pathway mediating the HS polarizing effect. In addition, the effects of DSbm on $G_{i}$ or $\rho$ ADP ribosylation were absent or small compared with those of SR 80037A.

The latter experiments suggested that SR 80037A acts at the level of the dendrites, inhibiting their initiation when added very early after seeding and possibly, as suggested by the ADP ribosylation of $\mathrm{G}_{\mathrm{i}}$ and $\rho$ in the dendrite-derived membranes, their elongation when added on already differentiated dendrites. To test the effect of SR 80037A on the growth of already initiated dendrites, the cells were plated and cultured for $24 \mathrm{hr}$ before the addition (or not) of SR 80037A and a further $24 \mathrm{hr}$ culture period (Fig. 10A). Figure $10 B$ illustrates that the addition of SR 80037A after $24 \mathrm{hr}$ in $\mathrm{Cdm}$ provokes cell rounding and reduces dendrite elongation in the following $24 \mathrm{hr}$ but does not modify the rate of axonal growth or the number of primary neurites. These results are in accordance with a specific effect of SR 80037A on the soma and at the level of dendritic growth cones.

\section{DISCUSSION}

The synthesis of proteoglycans (PGs) and GAGs during development is highly regulated (for review, see Small et al., 1996). In vivo expression patterns suggest that these compounds have important functions, for example, at the border of developmental 

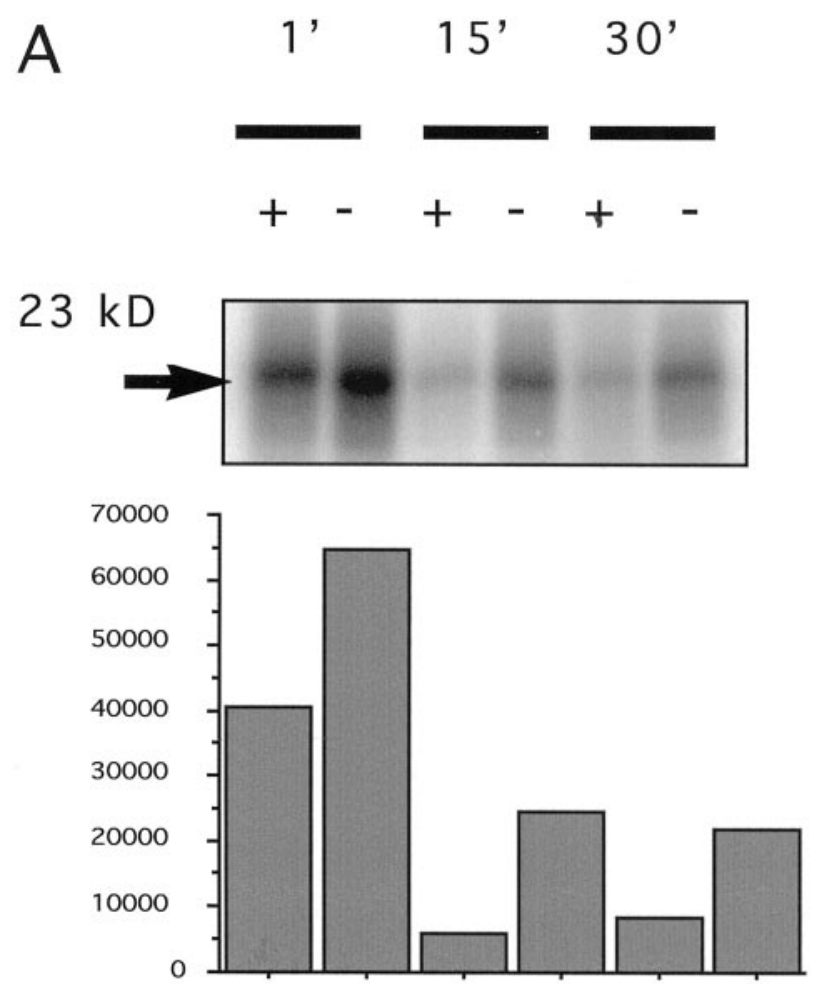
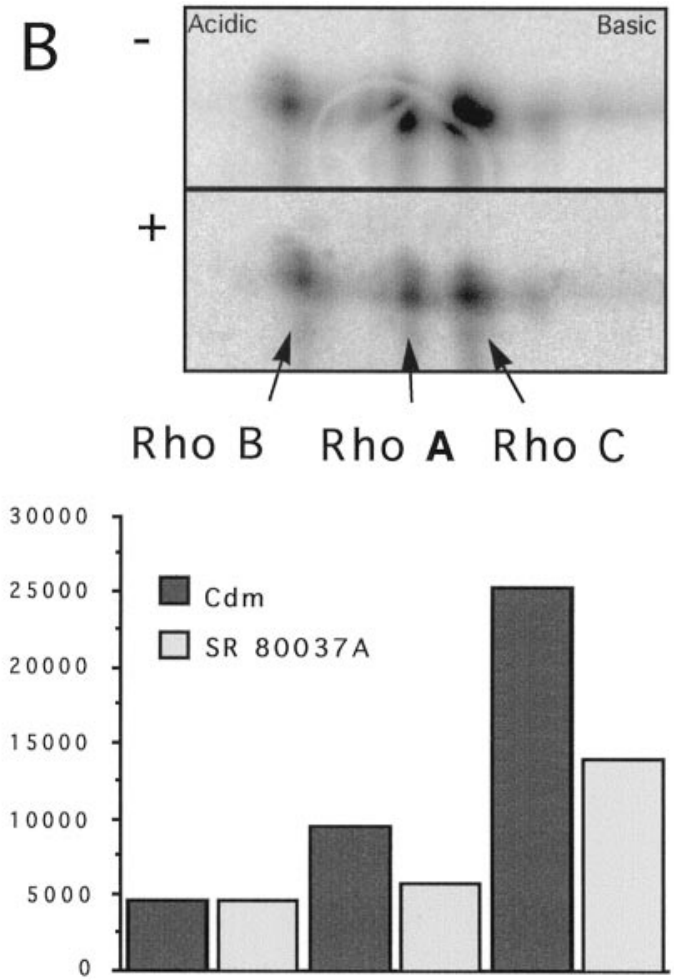

Figure 7. $\rho \mathrm{A}$ is in the SR $80037 \mathrm{~A}$ pathway. $A$, ADP ribosylation by $\mathrm{C} 3$ of a $21 \mathrm{kDA}$ protein in neuronal membranes pretreated (+) or not $(-)$ with $\mathrm{SR}$ 80037A during 1, 15, or $30 \mathrm{~min}$ and quantification by phosphoimager (bottom panel). This experiment is representative of five independent experiments using two different preparations of toxin in which SR 80037A reduced $\rho$ ADP ribosylation by 70 and $64 \%$ (preparation 1) and by 40, 42, and 46\% (preparation 2) after $30 \mathrm{~min} . \mathrm{B}$, Separation by two-dimensional gel electrophoresis of $\rho \mathrm{A}, \rho \mathrm{B}$, and $\rho \mathrm{C}$ demonstrating that SR 80037A (+) affects $\rho \mathrm{A}$ and $\rho \mathrm{C}$ ADP ribosylation but not that of $\rho \mathrm{B}$. Gels in top panel and quantifications by phosphoimager in bottom panel.

A

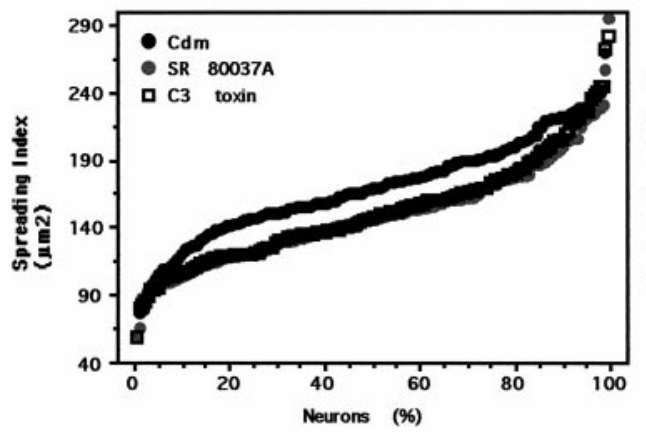

B

Figure 8. C3 and SR 80037A have identical effect on neuronal morphology. $\mathrm{Cu}-$ mulative distributions according to spreading index $(A)$, axon length $(B)$, and dendrite length $(C)$, as well as the number of primary neurites $(D)$ demonstrate that SR 80037A and C3 have similar effects on the morphology of E16 rat cortical neurons. $p<0.0001$, Cdm versus SR 80037A (spreading) and $p<0.001$ Cdm versus C3 (spreading). For all other parameters, see Table 1.

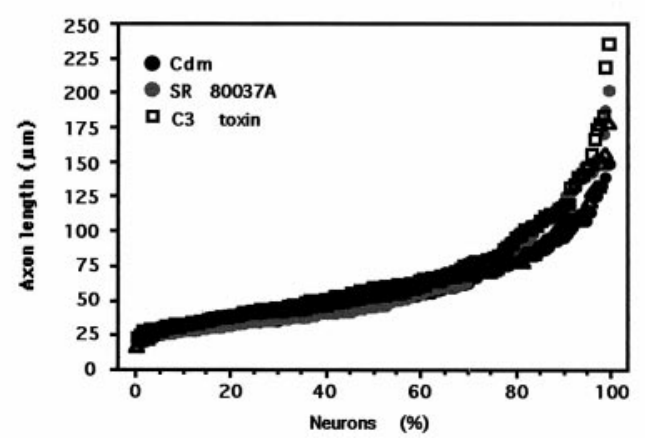

C

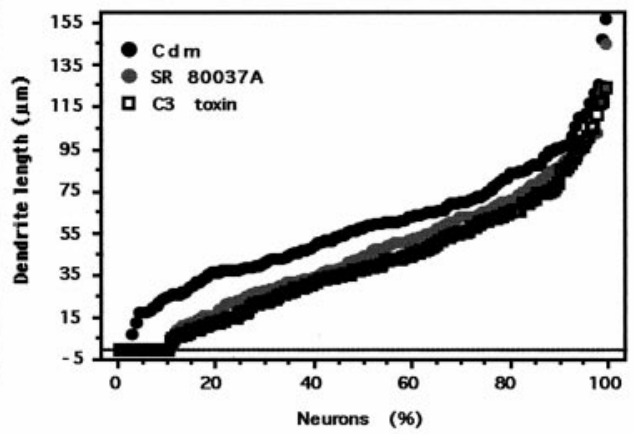

D 

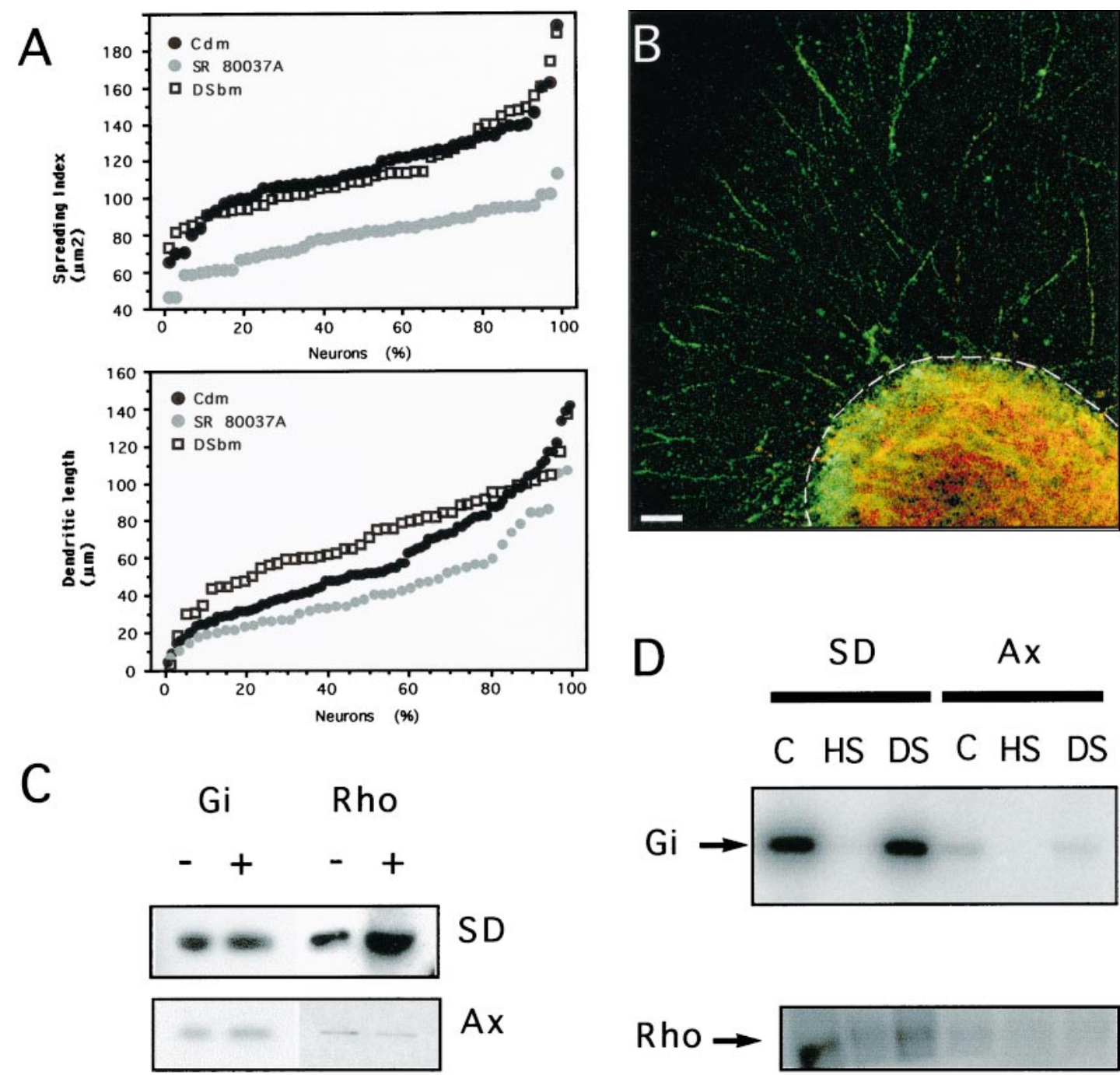

Figure 9. SR 80037A signaling pathway is specifically activated in the somatodendritic compartment and does not respond to DSbm. $A$, As opposed to SR 80037A, DSbm does not provoke cell rounding (top panel) and increases dendrite elongation (bottom panel). $p<0.0001$, SR 80037A/Cdm (spreading); $p<0.5$, DSbm versus Cdm (spreading). For all other parameters, see Table 1. B, Double MAP2/ $\tau$ staining of an explant having developed for $100 \mathrm{hr}$ in a collagen gel. Note the separation between axons invading the gel and dendrites that remain within the explant. Dotted lines indicate how somatodendritic and axonal compartments were separated. $C$, Western blot analysis of the axonal $(A x)$ and somatodendritic (SD) compartments demonstrates that for an equal amount of membrane proteins the SD compartment is highly enriched in $\mathrm{G}_{\mathrm{i}}$ and $\rho$ and that the addition of SR 80037A does not induce the degradation of either molecule. $D$, Incubation of equal amounts of somatodendritic $(S D)$ or axonal $(A x)$ membranes with SR $80037 \mathrm{~A}$ $(H S)$ or DSbm $(D S)$ followed by ADP ribosylation of $\mathrm{G}_{\mathrm{i} \alpha}$ (top panel) or $\rho$ (bottom panel) demonstrates that the signaling pathway is enriched in the somatodendritic compartment and does not respond to DSbm.

territories, as illustrated by the high concentration of a specific chondroitin sulfate at the inter-rhombomeric frontier (Heyman et al., 1995) or around the somatosensory barrels (Faissner and Steindler, 1995). PGs and GAGs have been shown to regulate neurite elongation in vitro and in vivo (Oohira et al., 1991; Lafont et al., 1992; Brittis and Silver, 1994; Faissner et al., 1994; FernaudEspinosa et al., 1994) and are upregulated after lesions of the nervous system, suggesting a role during growth and regeneration (Bovolenta et al., 1993; Gates et al., 1996). However, despite the suspected biological importance of PGs and GAGs, very little is known regarding their mode of action, and several hypotheses have been proposed.

A first possibility, illustrated by the direct activation, in the absence of FGF, of FGF receptor 4 by heparin (Gao and Goldfarb, 1995) is that they act as bona fide growth factors with specific receptors and signal transduction pathways. A second hypothesis well substantiated in the case of TGF- $\beta$ and FGF-1 or -2 (for review, see Ruoslathi and Yamaguchi, 1991) is that GAGs associate with growth factors, modulate their diffusion, prevent their degradation, and help their presentation to specific receptors (Schlessinger et al., 1995). A third proposed mode of action is through binding to other matrix molecules, for example, laminin (Smalheiser and Kim, 1995), and to cell or substrate adhesion molecules (Hayashi et al., 1992).

Here, we used SR 80037A, an HS with specific and saturable neuronal binding sites (Lafont et al., 1994), to investigate the HS signaling pathway involved in the induction of the axonal phenotype (specific reduction in dendrite number and length) in a well established model of cell polarity (Prochiantz, 1995). We show that SR $80037 \mathrm{~A}$ acts through a pathway involving heterotrimeric G-proteins, one or several PKCs, and $\rho$ GTPases. In addition, we have localized the SR $80037 \mathrm{~A}$-responsive pathway to the soma- 
A

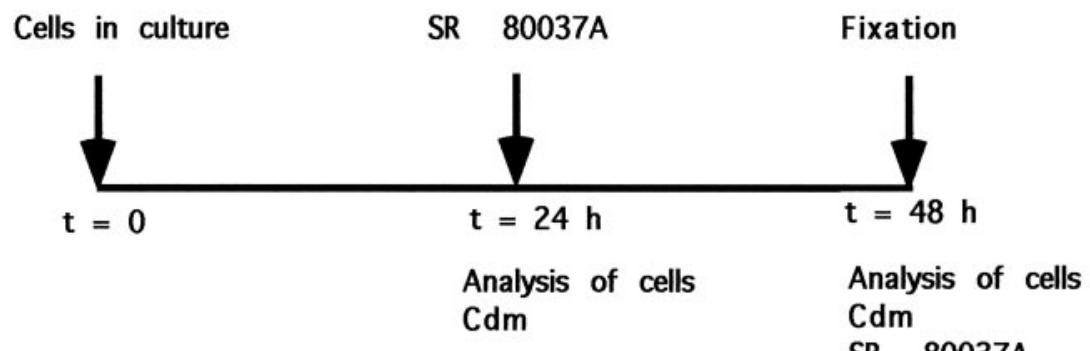

SR $80037 \mathrm{~A}$

B 1

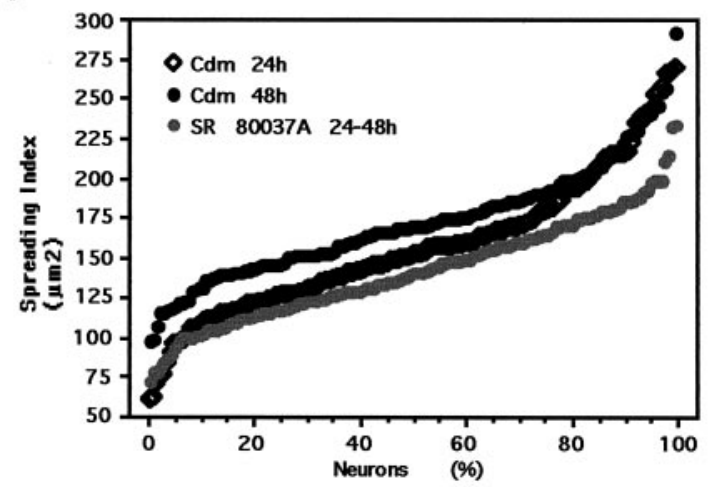

B3

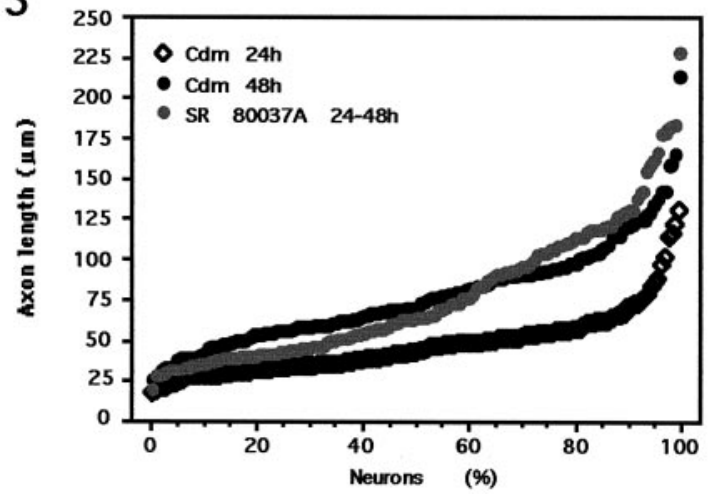

B2

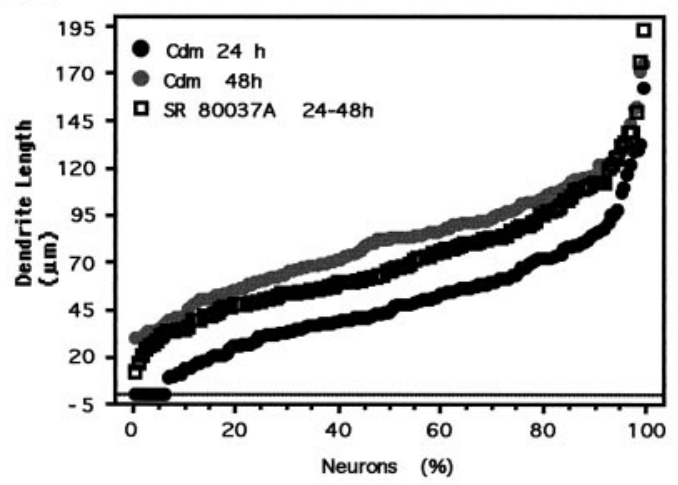

B4

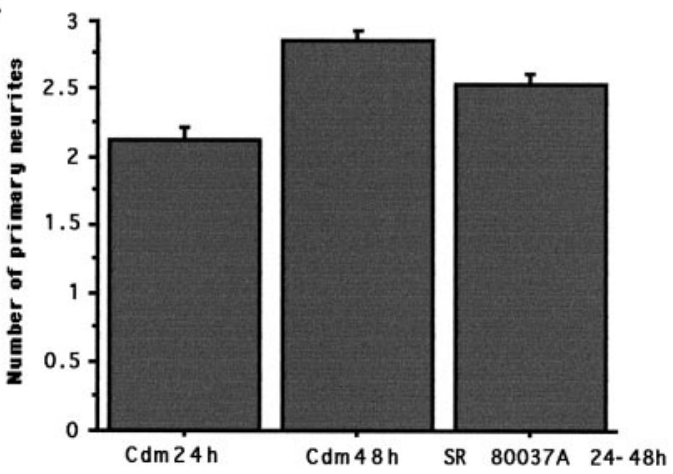

Figure 10. SR 80037A is active on already differentiated neurons. A, SR 80037A was added (or not) after $24 \mathrm{hr}$, and the cells were fixed or culture for another $24 \mathrm{hr}$. B1, Soma spreading increases between 24 and $48 \mathrm{hr}$ in Cdm but decreases in SR 80037A. $p<0.002$, Cdm $24 \mathrm{hr}$ versus Cdm $48 \mathrm{hr} ; p<$ $0.0001, \mathrm{Cdm} 48 \mathrm{hr}$ versus SR 80037A 24-48 hr; $p<0.003$, Cdm $24 \mathrm{hr}$ versus SR 80037A $48 \mathrm{hr}$. B2, Dendrite length between 24 and $48 \mathrm{hr}$ increases less in SR 80037A than in Cdm. $p<0.02 \mathrm{Cdm} 48 \mathrm{hr}$ versus SR 80037A 24-48 hr. B3, Axonal elongation is not modified between 24 and $48 \mathrm{hr}$ by the addition of SR 80037A. $p<0.9, \mathrm{Cdm} 48 \mathrm{hr}$ versus SR 80037A $24-48 \mathrm{hr}$. B4, The number of primary neurites is not modified between 24 and $48 \mathrm{hr}$ by the addition of SR 80036A. $p<0.1 \mathrm{Cdm} 48 \mathrm{hr}$ versus SR 80037A 24-48 hr.

todendritic compartment and shown that a dermatan sulfate (DSbm), which does not inhibit SR 80037A neuronal binding, does not activate the same pathway. Our results strongly suggest the existence of receptors highly enriched at the surface of soma and dendrites, responsible for the active inhibition of soma spreading and dendrite elongation and activated in the presence of SR 80037A.

SR 80037A is a heparin-derived GAG of average MW of 6000 $\mathrm{Da}$, devoid of anticoagulant activity. It can be obtained in large quantities, and its purification procedure eliminates all possibilities of contamination by peptides or compounds not related to heparin (Petitou et al., 1992; Petitou and van Boeckel, 1993). More importantly, SR 80037A reproduces the physiological properties of HS GAGs purified from astrocyte-conditioned medium
(Lafont et al., 1992) and of all active HS-like synthetic GAGs (Lafont et al., 1994). Furthermore, SR 80037A binding to the surface of neurons in culture demonstrated the existence of a limited number of binding sites $\left(3-5 \times 10^{5}\right.$ per embryonic neuron) with a $K_{\mathrm{D}}$ of $1 \mu \mathrm{M}$. Finally, SR $80037 \mathrm{~A}$ binding was displaced by heparin and HS-derived synthetic GAGs but not by DSbm, a dermatan sulfate from bovine mucosa, which, in contrast with HS GAGs, does not inhibit dendrite growth (Lafont et al., 1992, 1994). SR 80037A is, thus, an ideally suited compound to start investigating the transduction pathway involved in HS GAG signaling.

The pharmacological tools used in this study are either classical or prepared in the laboratory by exploiting the capability of permeant peptides and phosphopeptides derived from the third 


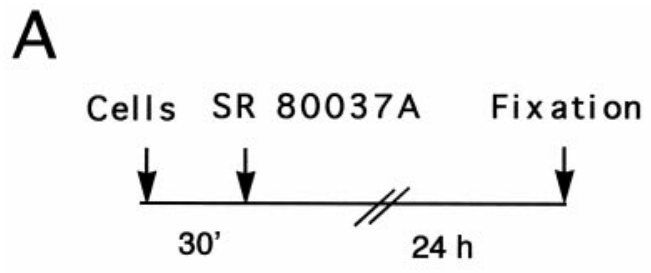

$\mathrm{Cdm}$
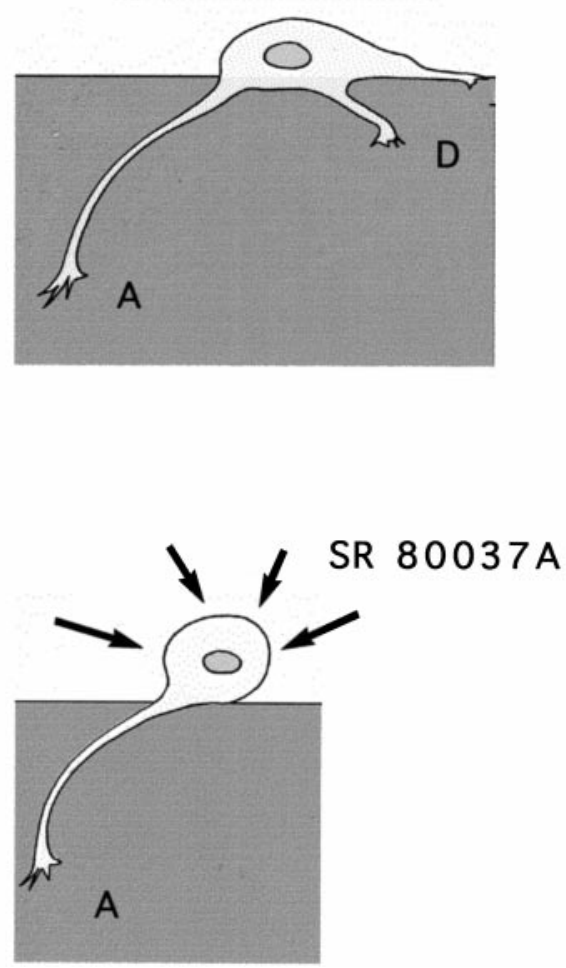

B
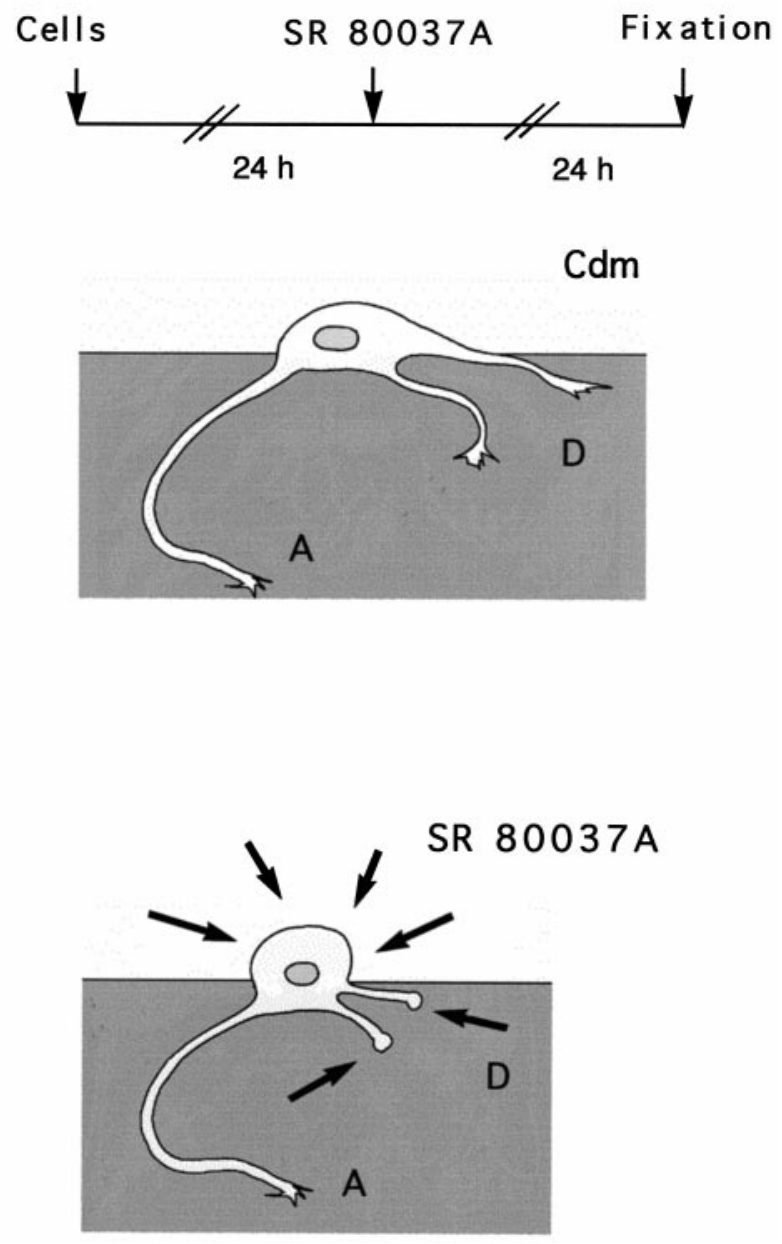

Figure 11. Hypothetical scheme. A, Specific binding of SR 80037A provokes cell rounding and drives the cells into a state in which dendrite initiation is not possible. In contrast, the axon can still initiate and elongate. This suggests that axons differ from dendrites very early in the course of neuronal differentiation. $B$, The addition of SR 80037A $24 \mathrm{hr}$ after the major neurites have started to grow provokes cell rounding and stops dendrite elongation but has no effect on axonal growth. This suggests that initiation and elongation of dendrites are sensitive to the addition of SR 80037A and lends weight to the idea that the soma is already polarized at the time of neurite initiation.

helix of Antennapedia homeodomain to translocate across biological membranes (Derossi et al., 1994, 1996, 1998). The advantage of this procedure is that the peptides show no toxicity, are internalized by $100 \%$ of the neurons, and gain direct access to the cytoplasmic compartment. The use of the latter pharmacological tools associated to that of a transgenic mouse in which a dominant negative FGF receptor was expressed in postmitotic neurons under the transcriptional control of the neural specific enolase promoter (Safell et al., 1997) eliminated the possibility that FGF, EGF, or PDGF receptors are involved in the signaling pathway. The absence of serum and the high dilution conditions of the culture make it also very unlikely that SR 80037A signals through a TGF-related receptor. Because NCAM, N-cadherin, and L1 signal through FGF-R1 (Safell et al., 1997), we feel that these three transmembrane molecules can also be tentatively eliminated from the list of candidates mediating SR 80037A activity. Our experiments, thus, lead to the conclusion that SR 80037A, after its specific binding to an unidentified binding site, signals through a cascade involving, in this order, heterotrimeric $\mathrm{G}_{i}, \rho$, and one or several PKC or PKN.

This pathway is reminiscent of that described for lisophospha- tidic acid (LPA) and leads to a phenotype that also resembles that described on neuronal cell lines incubated with LPA (Jalink et al., 1994; Moolenaar et al., 1997). Indeed, LPA after binding to an unknown receptor activates $G_{i}$ and $\rho$, induces the formation of actin stress fibers, and provokes growth cone collapse and cell rounding (Zhang et al., 1997). A striking similarity with SR $80037 \mathrm{~A}$ is a very rapid cell-rounding phenotype. The results obtained with LPA and SR 80037A are in agreement with the observation that $\mathrm{C} 3$, a bacterial toxin that ADP ribosylates $\rho$, inhibits the formation of dendrites by neocortical neurons (Threadgill et al., 1997).

The effect of SR 80037A on neuronal rounding and dendrite initiation does not require that SR $80037 \mathrm{~A}$ be present for $>1 \mathrm{hr}$. It is, thus, conceivable that, after SR 80037A addition, a pathway is activated that maintains the cell, at least for $19 \mathrm{hr}$, in an HS phenotype (cell rounding and no dendrites growing). No protein synthesis is required for the immediate rounding phenotype because it is preserved in the presence of cycloheximide. In contrast, the long-term effect, illustrated by the inhibition of dendrite elongation, requires protein synthesis. This suggests an accumulation of transiently active intracellular signals that acti- 
vates the synthesis of downstream effectors. The nature of the signals has not been investigated in detail. We could eliminate $\mathrm{NF}-\kappa \mathrm{B}$ because, although the latter factor is present in the cell cytoplasm, the addition of SR 80037A does not induce its nuclear translocation (data not shown; Perona et al., 1997). In contrast, preliminary results suggest that SR 80037A interferes with MAP-K activity (S. Calvet, M. Petitou, and A. Prochiantz, unpublished results).

Finally, we have developed an assay allowing the direct assessment of SR 80037A activity on membranes derived purely from axons or from a combination of somas, dendrites, and some axons. A striking result is that the inhibition of $\mathrm{G}_{\mathrm{i} \alpha}$ or $\rho$ ADP ribosylation, taken as evidence for SR 80037A signaling, occurs only in somatodendritic membranes, an observation in good accordance with a role of $\rho$ on dendritic remodeling (Threadgill et al., 1997). Furthermore, the inhibition of $\rho$ and $\mathrm{G}_{\mathrm{i} \alpha}$ ADP ribosylation by GAGs is specific, because it is not observed with a DS-type GAG that does not recognize the neuronal binding sites for SR 80037A (Lafont et al., 1994) and does not inhibit dendrite elongation.

Our results can be discussed in the frame of the model schematized in Figure 11 (for details, see Prochiantz, 1995). In this model, there exists a threshold of spreading below which dendrite growth is inhibited, whereas axonal elongation is still possible. We propose that SR 80037A, by its effect on cell rounding, drives the cell into a no-dendrite state still allowing axonal elongation (Fig. 11A). Because the cells are put in culture at the neuroblast stage (E16 rat or mouse embryos), this suggests that the conditions necessary for axonal elongation differ already at the neuroblast stage from those necessary for dendritic elongation and, therefore, that neuronal polarity preexists well before it is materialized under the form of true axons and dendrites. This proposal is supported by the addition of SR 80037A on cells that have already differentiated for $24 \mathrm{hr}$ (Fig. 11B), suggesting that the sugar has a similar stop-growth effect on the initiation of dendrites (Fig. 11A) and on their elongation (Fig. 11B). The physiological consequences of these observations might be of importance, because they suggest that PGs or GAGs could act as regulators of dendrite growth and that borders might exist that would specifically restrict dendritic development but could be ignored by elongating axons.

\section{REFERENCES}

Bovolenta P, Wandosell F, Nieto-Sampedro M (1993) Characterization of a neurite-outgrowth inhibitor expressed after CNS injury. Eur J Neurosci 5:454-465.

Brabet P, Pantaloni C, Rodriguez M, Martinez J, Bockaert J, Homburger V (1990) Neuroblastoma differentiation involves the expression of two isoforms of the $\alpha$-subunit of Go. J Neurochem 54:1310-1320.

Brittis PA, Silver J (1994) Exogenous glycosaminoglycans induce complete inversion of retinal ganglion cell bodies and their axons within the retinal neuroepithelium. Proc Natl Acad Sci USA 91:7539-7542.

Chamak B, Prochiantz A (1989) Influence of extracellular matrix proteins on the expression of neuronal polarity. Development 106:483-491.

Chamak B, Fellous A, Glowinski J, Prochiantz A (1987) MAP2 expression and neuritic outgrowth and branching are coregulated through region specific neuroastroglial interactions. J Neurosci 7:3163-3170.

Craig AM, Banker G (1994) Neuronal polarity. Annu Rev Neurosci $17: 267-310$.

Denis-Donini S, Glowinski J, Prochiantz A (1984) Glial heterogeneity may define the three-dimensional shape of mouse mesencephalic dopaminergic neurons. Nature 307:641-643.

Derossi D, Joliot AH, Chassaing G, Prochiantz A (1994) The third helix of Antennapedia homeodomain translocates through biological membranes. J Biol Chem 269:10444-10450.
Derossi D, Calvet S, Trembleau A, Brunissen A, Chassaing G, Prochiantz A (1996) Cell internalization of the third helix of the Antennapedia homeodomain is receptor-independent. J Biol Chem 271:18188-18193.

Derossi D, Chassaing G, Prochiantz A (1998) Trojan peptides: the penetratin system for intracellular delivery. Trends Cell Biol 8:84-87.

Faissner A, Steindler DA (1995) Boundaries and inhibitory molecules in developing neural tissues. Glia 13:233-254.

Faissner A, Clement A, Lochter A, Streit A, Mandl C, Schachner M (1994) Isolation of a neural chondroitin sulfate proteoglycan with neurite outgrowth promoting properties. J Cell Biol 126:783-799.

Fernaud-Espinosa I, Nieto-Sampedro M, Bovolenta P (1994) Differential effects of glycosaminoglycans on neurite outgrowth from hippocampal and thalamic neurones. J Cell Sci 107:1437-1448.

Gao G, Goldfarb M (1995) Heparin can activate a receptor tyrosine kinase. EMBO J 14:2183-2190.

Gates MA, Fillmore H, Steindler DA (1996) Chondroitin sulfate proteoglycan and tenascin in the wounded adult mouse neostriatum in vitro: dopamine neuron attachment and process outgrowth. J Neurosci 16:8005-8018.

Hall A (1998) Rho GTPases and the actin cytoskeleton. Science 279:509-513.

Hall H, Williams EJ, Moore SE, Walsh FS, Prochiantz A, Doherty P (1996) Inhibition of FGF-stimulated phosphatidylinositol hydrolysis and neurite outgrowth by a cell-membrane permeable phosphopeptide. Curr Biol 6:580-587.

Hayashi K, Madri JA, Yurchenco PD (1992) Endothelial cells interact with the core protein of basement membrane perlecan through $\beta 1$ and $\beta 3$ integrins: an adhesion modulated by glycosaminoglycan. J Cell Biol 119:945-959.

Heyman I, Faissner A, Lumsden A (1995) Cell and matrix specialisations of rhombomere boundaries. Dev Dyn 204:301-315.

Higgins D, Burack M, Lein P, Banker G (1997) Mechanisms of neuronal polarity. Curr Opin Neurobiol 7:599-604.

Imamura H, Tanaka K, Hirara T, Umikawa M, Kamei T, Takahashi K, Sasaki T, Takai Y (1997) Bni1p and Bnr1p: downstream targets of the Rho family small G-proteins which interact with profilin and regulate actin cytoskeleton in Saccharomyces cerevisiae. EMBO J 16:2745-2755.

Jalink K, van Corven EJ, Hengeveld T, Morii N, Narumiya S, Moolenaar WH (1994) Inhibition of lysophosphatidic- and thrombin-induced neurite retraction and neuronal cell rounding by ADP-ribosylation of the small GTP-binding protein Rho. J Cell Biol 126:801-810.

Lafont F, Rouget M, Triller A, Prochiantz A, Rousselet A (1992) In vitro control of neuronal polarity by glycosaminoglycans. Development 114:17-29.

Lafont F, Prochiantz A, Valenza C, Petitou M, Pascal M, Rouget M, Rousselet A (1994) Defined glycosaminoglycan motifs have opposite effects on neuronal polarity in vitro. Dev Biol 165:453-468.

Le Roux PD, Reh TA (1994) Regional differences in glial-derived factors that promote dendritic outgrowth from mouse cortical neurons in vitro. J Neurosci 14:4639-4655.

Lein P, Jonhson M, Guo X, Rueger D, Higgins D (1995) Osteogenic protein-1 induces dendritic growth in rat sympathetic neurons. Neuron 15:597-605.

Li J (1992) Bacterial toxins. Curr Opin Struct Biol 2:545-556.

Machesky LM, Hall A (1996) Rho: a connection between membrane receptor signalling and the cytoskeleton. Trends Cell Biol 6:304-310.

McAllister AK, Katz LC, Lo DC (1997) Opposing roles for endogenous BDNF and NT-3 in regulating cortical dendritic growth. Neuron 18:767-778

Moolenaar WH, Kranenburg O, Postma FR, Zondag GCM (1997) Lysophosphatidic acid: G-protein signalling and cellular responses. Curr Opin Cell Biol 9:168-173.

Neer EJ, Lok JM, Wolf LG (1984) Purification and properties of the inhibitory guanine nucleotide regulatory unit of brain adenylate cyclase. J Biol Chem 259:14222-14229.

Nonaka H (1995) A downstream target of RHO1 small GTP-binding protein is $\mathrm{PKC1}$, a homolog of protein kinase C, which leads to activation of the MAP kinase cascade in Saccharomyces cerevisiae. EMBO J 14:5931-5938.

Oohira A, Matsui F, Katho-Semba R (1991) Inhibitory effects of brain chondroitin sulfate proteoglycans on neurite outgrowth from PC12D cells. J Neurosci 11:822-827.

Perona R, Monatner S, Saniger L, Sanchez-Perez I, Bravo R, Lacal JC (1997) Activation of the nuclear factor- $\kappa \mathrm{B}$ by Rho, CDC42, and Rac-1 proteins. Genes Dev 11:463-475. 
Petitou M, van Boeckel CAA (1993) Chemical synthesis of heparin fragments and analogues. Prog Natl Prod Chem 60:143-215.

Petitou M, Coudert C, Level M, Lormeau JC, Zuber M, Simenel C, Fournier JP, Chay J (1992) Selective O-acylated glycosaminoglycan derivatives. Carbohydr Res 236:107-119.

Prochiantz A (1995) Neuronal polarity: giving neurons heads and tails. Neuron 15:743-746.

Qian J, Bull MS, Levitt P (1992) Target-derived astroglia regulate axonal outgrowth in a region-specific manner. Dev Biol 149:278-294.

Rousselet A, Fetler L, Chamak B, Prochiantz A (1988) Rat mesencephalic neurons in culture exhibit different morphological traits in the presence of media conditioned on mesencephalic or striatal astroglia. Dev Biol 129:495-504.

Rousselet A, Autillo-Touati A, Araud D, Prochiantz A (1990) In vitro regulation of neuronal morphogenesis and polarity by astrocytederived factors. Dev Biol 137:33-45.

Ruoslathi E, Yamaguchi Y (1991) Proteoglycans as modulators of growth factor activities. Cell 64:867-869.

Safell JL, Williams EJ, Mason IJ, Walsh FS, Doherty P (1997) Expression of a dominant negative FGF receptor inhibits axonal growth and FGF receptor phosphorylation stimulated by CAMS. Neuron 18:231-242.
Schlessinger J, Lax I, Lemmon M (1995) Regulation of growth factor activation by proteoglycans: what is the role of the low affinity receptors? Cell 83:357-360.

Smalheiser NR, Kim E (1995) Purification of cranin, a laminin binding membrane protein. J Biol Chem 270:15425-15433.

Small DH, San Mok S, Williamson TG, Nurcombe V (1996) Role of proteoglycans in neural development, regeneration and the aging brain. J Neurochem 67:889-899.

Theodore L, Derossi D, Chassaing G, Llirbat B, Kubes M, Jordan P, Chneiweiss H, Godement P, Prochiantz A (1995) Intraneuronal delivery of protein kinase $\mathrm{C}$ pseudosubstrate leads to growth cone collapse. J Neurosci 15:7158-7167.

Threadgill R, Bobb K, Ghosh A (1997) Regulation of dendritic growth and remodeling by Rho, Rac, and Cdc42. Neuron 19:625-634.

Williams EJ, Dunican DJ, Green PJ, Howell FV, Derossi D, Walsh FS, Doherty P (1997) Selective inhibition of growth factor-stimulated mitogenesis by a cell-permeable Grb2-binding peptide. J Biol Chem 272:22349-22354.

Zhang Q, Magnusson MK, Mosher DF (1997) Lysophosphatidic acid and microtubule-destabilizing agents stimulate fibronectin matrix assembly through Rho-dependent actin stress fiber formation and cell contraction. Mol Biol Cell 8:1415-1425. 